\title{
Flexible and robust laser-induced graphene heaters photothermally scribed on bare polyimide substrates
}

Marco R. Bobinger ${ }^{1, *}$, Francisco J. Romero ${ }^{2}$, Alfonso Salinas-Castillo ${ }^{3}$, Markus Becherer ${ }^{1}$, Paolo Lugli ${ }^{3}$, Diego P. Morales ${ }^{2}$, Noel Rodríguez ${ }^{2}$ and Almudena Rivadeneyra ${ }^{1} *$

${ }^{1}$ Institute for Nanoelectronics, Technical University of Munich, 80333 Munich, Germany

${ }^{2}$ Pervasive Electronics Advanced Research Laboratory (PEARL), Dept. Electronics and Computer Technology, University of Granada, 18071 Granada, Spain

${ }^{3}$ Dept. Analytical Chemistry, University of Granada, 18071 Granada, Spain

${ }^{4}$ Faculty of Science and Technology, Free University of Bolzano, 39100 Bolzano-Bozen, Italy

Corresponding author e-Mails: marco.bobinger@tum.de and almudena.rivadeneyra@tum.de

\begin{abstract}
We demonstrate the feasibility of fabricating cost-effective and robust laser-induced graphene (LIG) flexible heaters with an innovative technique based on the photothermal production of graphene with a foam-like morphology. The produced devices are precisely defined on a bare polyimide substrate without the need of photomasks by employing a computer numerical control (CNC) driven laser diode. The electrical properties of the LIG-based heaters can be tailored by adjusting the laser power. The resulting conductive material exhibits electrical and chemical properties which are similar to the ones for graphene such as a negative temperature coefficient of $-0.46 \mathrm{~m}^{\circ} \mathrm{C}^{-1}$ and a maximum operating temperature of around $400{ }^{\circ} \mathrm{C}$. The developed heaters can outperform the existing emerging technologies showing a very rapid and stable response up to $225^{\circ} \mathrm{C}$ with the extra features of flexibility, biocompatibility, and environmental friendliness.
\end{abstract}

Keywords: CNC laser; flexible; graphene film heater; laser-induced graphene; laser ablation; micro-hotplate, polyimide

\section{Introduction}

Heaters are resistive structures operating under the principle of Joule's heating that results in a self-heating effect. Tailor-made heating devices that are thin, flexible, mechanically or 
chemically robust are employed in many different applications ranging from gas sensing to microfluidics. In the former case, many gas sensors require high operating temperatures [1], [2] or they need to be actively recovered after being exposed to the target gas [3], [4]. For the active recovery, the heater is placed under the sensing element to achieve the required temperature to drive or to recover the sensor. One example of application can be found for microfluidic systems that carry out a polymerase chain reaction (PCR) on nucleotides of interest within microfluidic channels: a certain and precise temperature is needed to cultivate the biological samples to detect those nucleotides [5], [6].

Such devices have been conventionally fabricated based on silicon ( $\mathrm{Si}$ ) micromachining technologies [7], [8]. Also, there are examples where heaters have been integrated on porous silicon and glass substrates [9], [10]. In the last decades, the interest in flexible electronics has substantially been aroused [11]. In the case of the fabrication of heaters on flexible substrates, there are unique properties, i.e. mechanical flexibility and lower thermal conductivity, which cannot be found for devices based on rigid Si wafers [12]-[14]. For this kind of substrates, printing techniques are particularly interesting because of their scalable and low-cost fabrication in comparison with photolithography and etching processes that are commonly employed for Si-based devices. There are examples in the literature where heaters have been manufactured by inkjet printing of silver nanoparticles on polymeric films [15]-[17]. However, they are hindered at higher operation temperatures because of the non-stability due to electromigration and, in addition, their lifetime is limited by chemical degradation [18]. In other works, the use of metal nanowires (MNWs) such as silver (AgNW) and copper (CuNWs) nanowires deposited by spray deposition was reported for the production of transparent heaters [19], [20]. MNWs represent a very promising new material due to their high Figures of Merit (FoM) for the transparency and the sheet resistance that challenges the values for ITO. However, MNW-based heaters face important constraints for their use as robust and durable heaters [23]: i) CuNWs oxidize below a temperature of $100{ }^{\circ} \mathrm{C}$ [21], [22]; ii) the electromigration for AgNWs is critical at elevated electrical current densities; iii) the fragmentation temperatures for both materials are lowered substantially with regard to the melting points for the bulk counterparts. It should be noted that recently some authors have successfully considered the use of gold $(\mathrm{Au})$ based heaters to enhance the stability at different operating conditions and guarantee biocompatibility, but the material costs obviously pose a large obstacle for commercial purposes [23]. In detail, Khan et al. have reported aerosol jetted heaters based on Au-nanoparticles on a polyimide substrate that cover an area of around 1 $\mathrm{mm}^{2}$. Their heaters can operate at temperatures up to $250{ }^{\circ} \mathrm{C}$ with a power demand of 22 
$\mathrm{mW}$ [24]. These values yield to an increase in temperature over electrical power density of around $102{ }^{\circ} \mathrm{C} \mathrm{cm} / \mathrm{W}$, which is lowered by around $22 \%$ compared to the value reported in this work.

All the aforementioned examples are based on the deposition of a self-heating layer, and therefore, requiring additional post-processing techniques, such as drying, curing or sintering [25]. In this work, we describe a low-cost and one-step process to integrate heaters directly in polymeric films. In particular, we exploit the fabrication process previously described in [26], where graphene films with a foam-like morphology (Laser-Induced Graphene, LIG) are produced by the photothermal ablation of Kapton ${ }^{\circledR} \mathrm{HN}\left(\right.$ DuPont $\left.^{\mathrm{TM}}\right)$ polyimide using a laser diode driven by a CNC unit. As shown in the previous work, the electrical conductivity of the film can be tailored by adjusting the laser power. This technique offers four main advantages over the existing deposition or printing methods: i) high-precision patterns can be defined on the polyimide surface without affecting the unexposed areas and without the need of using lithographic masks; ii) the heaters are fabricated directly from the polyimide substrate without the need of any chemical reagent, being, therefore, a clean and environmentally friendly method; iii) the process is intrinsically inexpensive and scalable; iv) as shown in this work the performance of the heaters is very competitive. (Rev\#2Com\#1) So far, the laser ablation process has been utilized to produce graphene films for various applications such as supercapacitors [27], [28], polymer-written and on-skin electronics [28], oxygen electrocatalysis [29], water oxidation catalysts [30], electrochemical devices [31] and desalination [32]. In this work, we apply for the first time this versatile fabrication technique for the production of flexible heaters developing a comprehensive study of their structural, chemical electrical and mechanical properties. The paper is structured as follows. The fabrication method for the LIG films is briefly described in Section 2 along with the characterization techniques implemented. In Section 3, the results are presented starting with the characterization of the structural, chemical, electrical and thermal properties of the laserscribed heaters, including the modelling of its temperature response. Then, the films are tested as heaters, and the transient thermal response of the devices is investigated and discussed as well as benchmarked with commercial heaters. Finally, the robustness of the heaters is studied with respect to their maximum operating temperature, long-term stability and flexibility in operation and standing idle. 


\section{Materials and methods}

\subsection{Fabrication of the LIG films}

The samples were fabricated using Kapton ${ }^{\circledR} \mathrm{HN}$ polyimide films with a thickness of $125 \mu \mathrm{m}$ from DuPont ${ }^{\mathrm{TM}}$ as substrate and raw material. The conductive patterns were obtained through photothermal ablation of this polyimide film using an in-house developed CNC-driven laser (Rev\#1Com\#5) diode from Q-BAIHE ${ }^{\mathrm{TM}}$ (model: 405ML-300-2290). In particular, the substrate was located in a horizontal holder at a distance of $6 \mathrm{~cm}$ from the laser head, allowing a spatial resolution of about $20 \mu \mathrm{m}$ at a fixed wavelength of $405 \mathrm{~nm}$. As demonstrated in [26], a laser power of $100 \mathrm{~mW}$ constitutes the best trade-off between sheet resistance and the substrate stability in terms of thermal dissipation. At this power, LIG films with a sheet resistance below $250 \Omega / \mathrm{sq}$. were produced without inducing a plastic deformation on the substrate. Therefore, all samples were fabricated using this power value. (Rev\#1Com\#4) The sheet resistances were measured using a four-point probe head from Jandel connected to a B2901A Keysight source measuring unit (SMU). In order to establish electrical percolation , as shown in Figure 4, a constant current of $3 \mathrm{~mA}$ was sourced for all measurements.

\subsection{Measurement of the film morphology}

A 3D profile of the LIG film was acquired using a DekTak XT profilometer from Bruker (USA). Field-emission scanning electron microscope (FESEM) images were recorded using an NVision40 from Carl Zeiss (Germany) at an acceleration voltage of $7.0 \mathrm{kV}$ and an extraction voltage of $5.0 \mathrm{kV}$.

\subsection{Transient electrical and thermal measurements}

For the transient measurements, the LIG films were contacted with copper tape and conductive silver paint. The electrical input powers were applied and the data recorded using a LabVIEW controlled DC power supply 2200-30-5 from Keithley (USA) with a voltage and current resolution of $1 \mathrm{mV}$ and $0.1 \mathrm{~mA}$, respectively. Thermal images were recorded using a 640x480 px infrared (IR) camera Testo890 from Testo (Germany). Using the software IRSoft from Testo (Germany) and a MATLAB script, the temperature transients were extracted from processing the IR images. The resulting temperature values represent a mean temperature that was determined by averaging over an area on the heaters of around $2 \times 2 \mathrm{~mm}^{2}$. An accurate emissivity value $\varepsilon$ for the LIG films with $0 \leq \varepsilon \leq 1$ of 0.75 was determined by placing the LIG samples on a hot plate with a set-point temperature of $75^{\circ} \mathrm{C}$. Subsequently, the temperature of the LIG film was measured using a contact technique, i.e. a Pt100 
thermoresistor, and the emissivity reading of the IR camera was adjusted such that the camera displayed temperature matches the measured one.

\subsection{Bending test}

A custom bending setup was designed and built for the bending tests. The setup consists of a LabVIEW 2016 controlled stepper motor (PD4-N5918M4204) equipped with a precision planetary gear (GPLE60) from Nanotec (Germany) that slides the movable clamp along an aluminum rail. The samples are mounted in the insulating Polyoxymethylene (POM) clamps and connected to a LabVIEW controlled Keithley 2700 multimeter from Keithley (USA). For the bending tests, the bending speed and minimum bending diameter were kept constant at $10 \mathrm{~mm} / \mathrm{s}$ and $4 \mathrm{~mm}$, respectively.

\subsection{X-ray photoelectron spectroscopy}

X-ray photoelectron spectroscopy (XPS) measurements were performed at a base pressure of $5 \cdot 10^{-10}$ mbar with a monochromatic aluminum $K_{\alpha}$ anode as a x-ray source at an operating power of $350 \mathrm{~W}$. The high resolution spectra were acquired using a SPECS Phoibos hemispherical analyser at a pass-energy of $20 \mathrm{eV}$ with an energy resolution of $0.05 \mathrm{eV}$.

\section{Results and discussion}

In this section, we first show the structural, chemical electrical and thermal properties of the heaters fabricated by laser ablation of polyimide films. After that, the thermal stability of the devices is presented and finally, their response during bending cycles is shown.

\subsection{Structural, chemical, electrical and thermal properties}

Mechanical profilometer scans of the LIG over an area of $1 \mathrm{x} 1 \mathrm{~mm}^{2}$ are shown in Figure 1 (a) along with the line profiles in (b) $\mathrm{x}$ - and (c) y-direction, in accordance with the dashed lines drawn to Figure 1 (a). From the height profile and the optical image in the inset in Figure 1 (a), the mesh-like structure of the LIG film can be recognized. A mean height of $18.7 \pm 2.2 \mu \mathrm{m}$ was determined for the LIG lines after considering the data of the indicated $x-y$ line profiles. The reticulated pattern of the laser scribing process shown in Figure 1 (a) and in the SEM-image below in Figure 7 (c) is a direct consequence of the mechanical step size of the utilized CNC unit, which is larger than the spot size of the laser focused on the surface. This fact limits the surface coverage and, in turn, the minimum sheet resistance that can be achieved. 

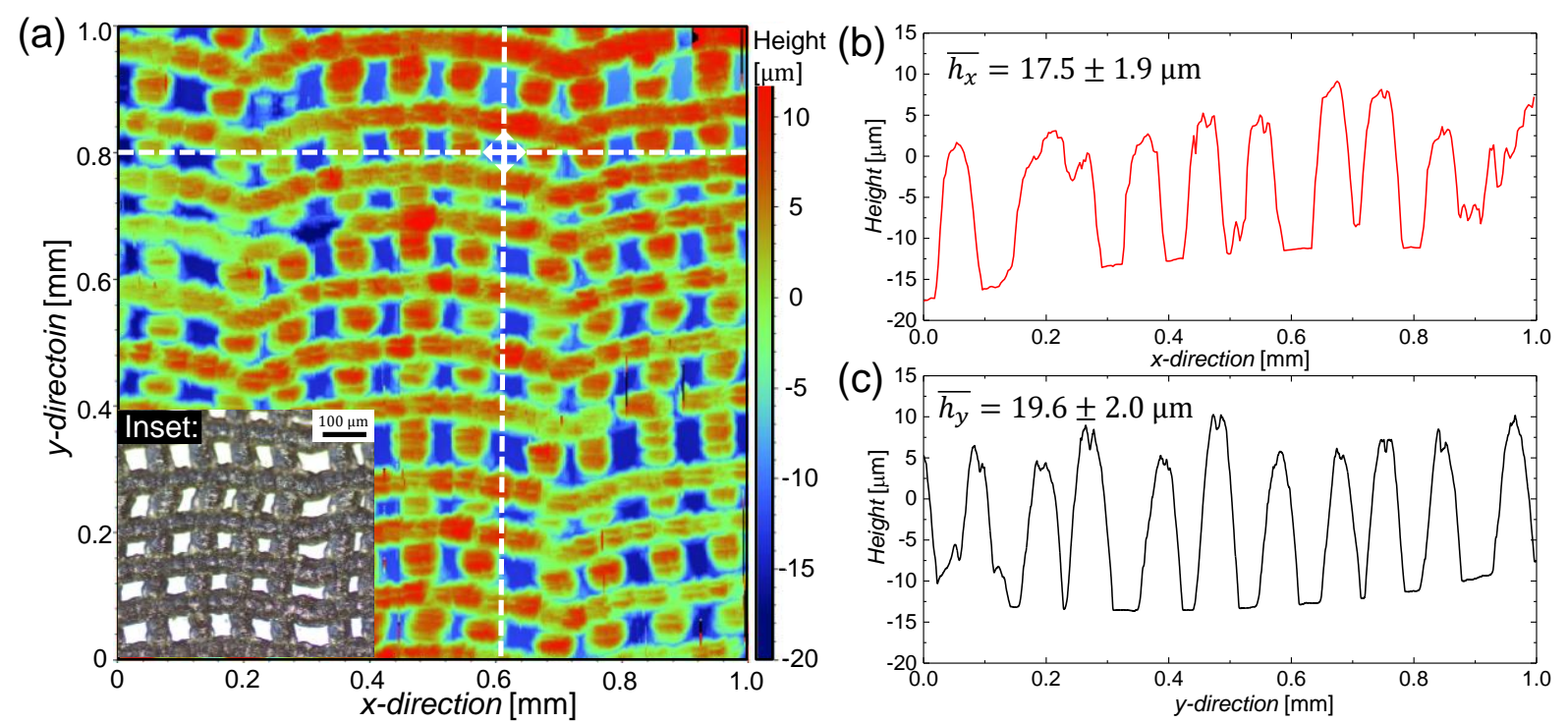

Figure 1. (a) Profilometer scan for a LIG film on polyimide substrate over an area of $1 \mathrm{x} 1 \mathrm{~mm}^{2}$. The inset shows a microscope image of the same sample. Line profiles in (b) $\mathrm{x}$ - and (c) y-direction were drawn in accordance with the arrows and dashed lines indicated in (a).

Further, the chemical alterations that are induced by the laser ablation process have been studied by X-ray photoelectron spectroscopy (XPS), which allows extracting concentrations for the elements and identifying changes in the carbon-oxygen compounds. Survey scans, as well as high-resolution XPS spectra for the $\mathrm{C} 1 \mathrm{~s}, \mathrm{~N} 1 \mathrm{~s}$ and $\mathrm{O} 1 \mathrm{~s}$ peak, are shown in the supporting information in Figure S1 and Figure S2, respectively. In accordance with the expectation that a graphene material is produced, the laser ablation process leads to an increase of the relative carbon content from $78 \%$ before to $85 \%$ after laser ablation, whereas the oxygen content decreases from $18 \%$ to $10 \%$. Besides the change in the elemental composition, also a modification of the carbon-oxygen compounds can be observed. To understand this effect, the high-resolution C 1s spectra for the polyimide substrate (Kapton ${ }^{\circledR} \mathrm{HN}$ ) are depicted in Figure 2 (a) before and (b) after laser ablation.
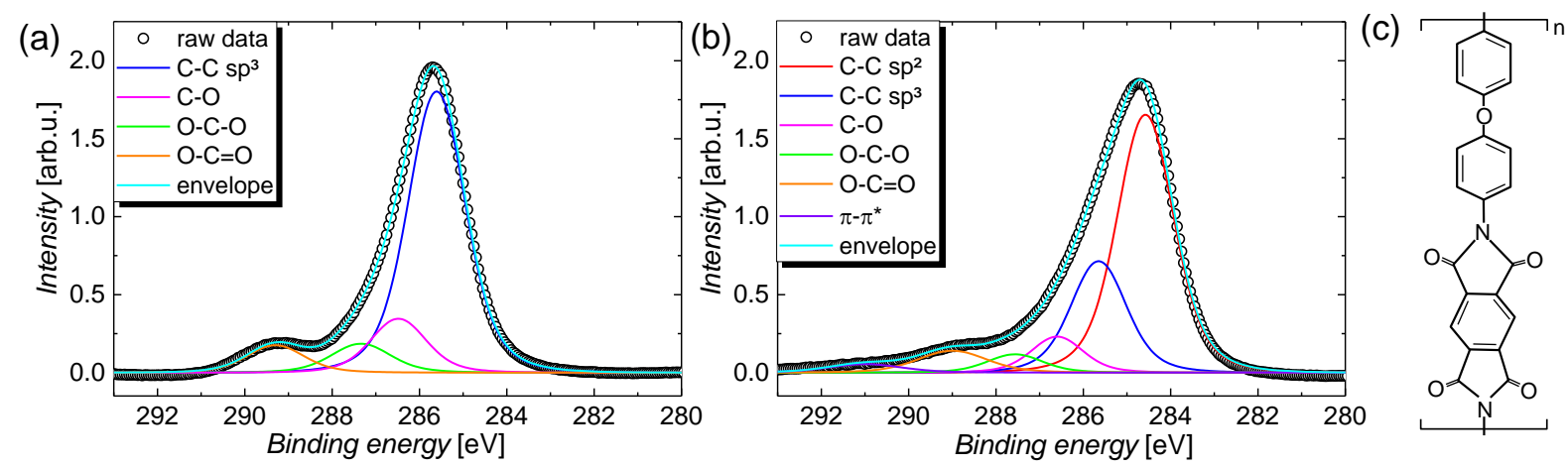

Figure 2. High-resolution XPS spectra for the C 1s core level (a) before and (b) after laser ablation. (c) Structural formula for the polyimide substrate (Kapton®HN) with the chemical formula $\mathrm{C}_{22} \mathrm{H}_{11} \mathrm{~N}_{2} \mathrm{O}_{5}$. 
After a careful comparison of the extensive literature for carbon-related XPS spectra [33][38] including the few reports on Kapton ${ }^{\circledR} \mathrm{HN}$ [39], [40] , the $\mathrm{C} 1 \mathrm{~s}$ raw spectra were deconvoluted into its different contributions, which are associated with $\mathrm{C}-\mathrm{C} \mathrm{sp}^{2}$ hybridized carbon bonds (284.6 eV), C-C sp ${ }^{3}$ hybridized carbon bonds $(285.6 \mathrm{eV})$, the carbon-oxygen compounds C-O (286.6 eV), O-C-O $(287.6 \mathrm{eV})$ and $\mathrm{O}-\mathrm{C}=\mathrm{O}(289 \mathrm{eV})$ as well as $\pi-\pi^{*}$ transitions $(291 \mathrm{eV})$. For the untreated polyimide substrate, a large contribution of $\mathrm{sp}^{3}$ hybridized carbon atoms and carbon-oxygen compounds from the aromatic rings can be seen, in accordance with the structural formula of the polyimide shown in Figure 2 (c).

The extracted concentrations before and after ablation for $\mathrm{sp}^{2}$ and $\mathrm{sp}^{3}$ hybridized carbon and the carbon-oxygen compounds are summarized in Table S1. From this summary, it can be concluded that, after ablation, the concentrations of carbon-oxygen compounds and $\mathrm{sp}^{3}$ hybridized carbon decreased, which goes along with the appearance of a large content of $\mathrm{sp}^{2}$ hybridized carbon. This formation of $\mathrm{sp}^{2}$ hybridized carbon is a clear indication for the production of amorphous graphene-derived species [41], [42] and gives rise to the name of the material, i.e. laser-induced graphene.

As previously shown, the laser writing breaks the carbon-nitrogen and carbon-oxygen compound bonds, i.e. $\mathrm{C}-\mathrm{N}, \mathrm{C}-\mathrm{O}-\mathrm{C}$, and $\mathrm{C}=\mathrm{O}$, that are the main contributions for the polyimide substrate [26]. The observed decrease in the portion of oxygen-containing carbon compounds is also in agreement with the overall decrease in oxygen species shown in the high-resolution spectra in Figure S2.

Next, the electrical properties of the LIG material are explored. For this, the I-V curves for two LIG heaters with different active areas were recorded and displayed in Figure 3 (a). From the relatively constant resistance-current behavior shown in Figure 3 (b), it can be recognized that the LIG heaters show an ohmic behavior. Both LIG films were fabricated using the same parameters and show a sheet resistance of around $250 \Omega / \mathrm{sq}$. The difference in resistance of the LIG films arises due to the different electrode dimensions that are formed after contacting with copper tape and conductive silver paint. However, two additional effects can be identified: i) the resistance shows a drastic drop for low currents and ii) the resistance is slightly and gradually lowered for increasing currents. The first effect can be ascribed to the onset of electrical percolation that requires a finite current density, whereas the latter effect can be explained by the current induced heating of the LIG film. The increase in temperature leads to a reduction in resistance and will be discussed later. 

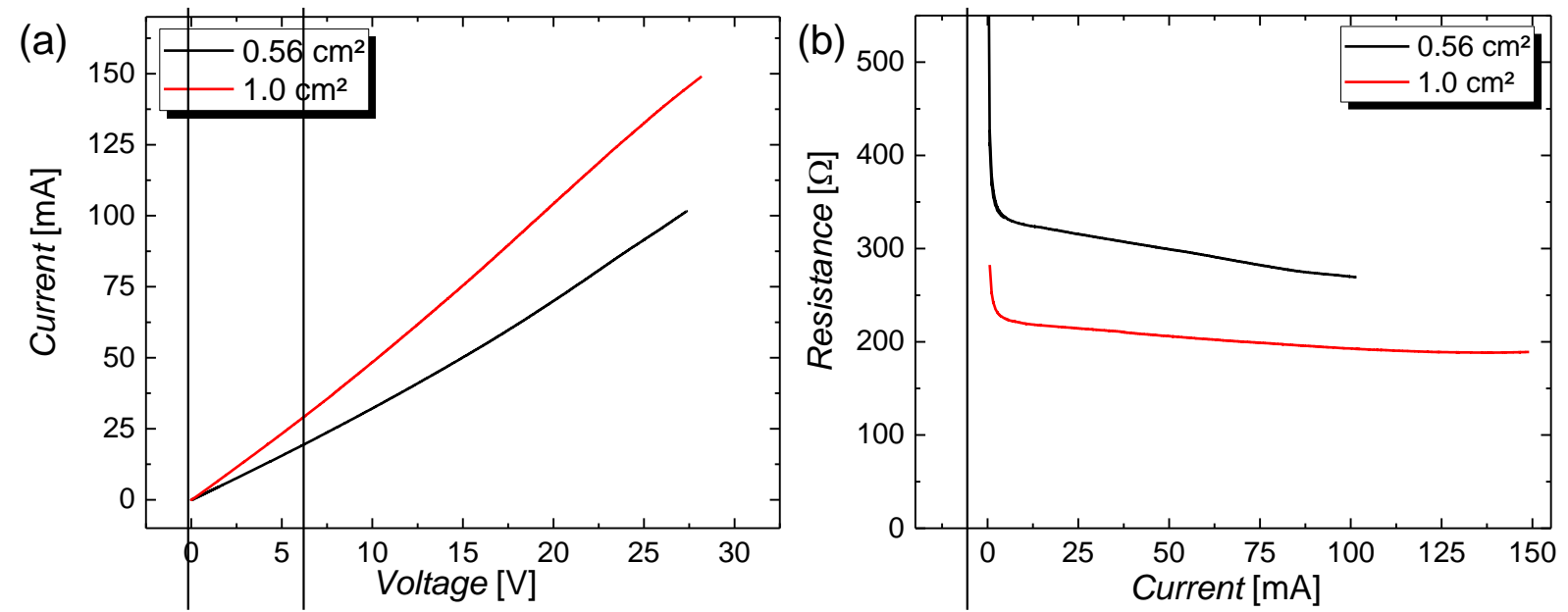

Figure 3. (a) Current-voltage (I-V) curves for two LIG films with different heated areas on a polyimide substrate. (b) Resistances for the two LIG films as a function of the sourced current.

Next, the onset of electrical percolation was studied in more detail; Figure 4 shows the resistance of a LIG heater for step-wise increases of the current as a function of time. The first finite resistance of around $328 \Omega$ could be recorded around a current of $0.59 \mathrm{~mA}$, which corresponds to a current density of $5.9 \mathrm{~A} / \mathrm{m}^{2}$. For increasing currents and current densities of $10 \mathrm{~mA}$ and $100 \mathrm{~A} / \mathrm{m}^{2}$, respectively, the measured resistance value shows a reduction of around $26 \%$ compared to the first recording, leading to a resistance of $243 \Omega$. The drop in resistance is not ascribed to the resistance-temperature behavior that, for graphitic materials yields to a negative temperature coefficient [43], but to the requirement for a finite current density to establish electrical percolation. This effect has already been observed by Bellew et al. [44] who contacted individual silver nanowire junctions and found a current of around $1-$ $10 \mu \mathrm{A}$ to be required to establish percolation. In their work, this effect was compared with the electroforming process in resistive switching materials that is required to generate an initial conductive state [45]. 


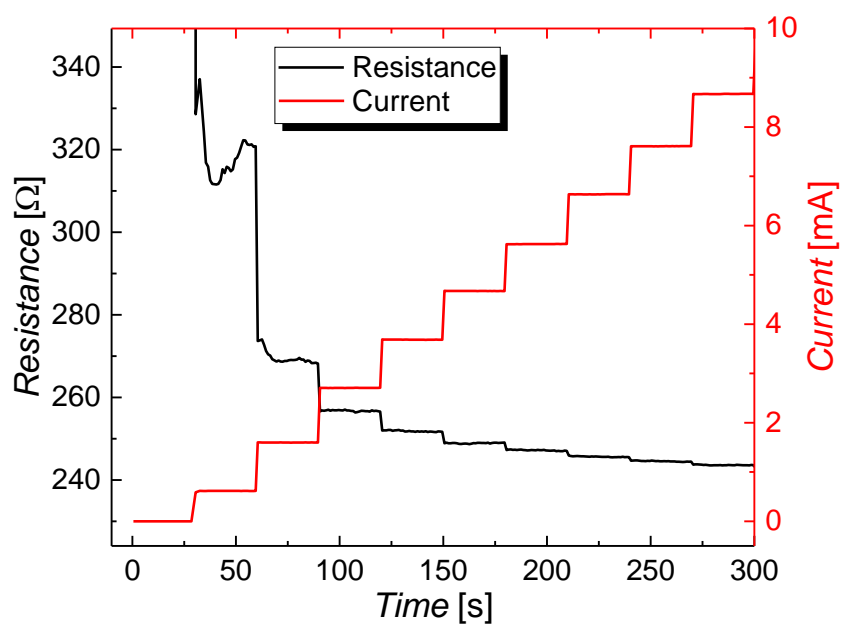

Figure 4. Resistance and current of a LIG film as a function of the time. The measurement was conducted to study the percolation onset of LIG films at low currents.

The transient response of LIG based thin film heaters for increasing powers is shown in Figure 5 for (a) the temperature and (b) the resistance. It can be recognized that the resistance response follows the overall trend of the temperature response. The rise in temperature as a function of the effectively heated area of the LIG film/polyimide substrate is illustrated in Figure 5 (c) and shows an almost linear behavior with a slope that yields to $131 \pm 5$ ${ }^{\circ} \mathrm{C} \cdot \mathrm{cm}^{2} / \mathrm{W}$. This value compares well or it is superior to the ones reported for AgNWs 134 $179{ }^{\circ} \mathrm{C} \cdot \mathrm{cm}^{2} / \mathrm{W}$ [46], [47], ITO $\left(88-388{ }^{\circ} \mathrm{C} \cdot \mathrm{cm}^{2} / \mathrm{W}\right)$ [47]-[49], or CNTs $(27-212$ $\left.{ }^{\circ} \mathrm{C} \cdot \mathrm{cm}^{2} / \mathrm{W}\right)[50]-[52]$.

(a)
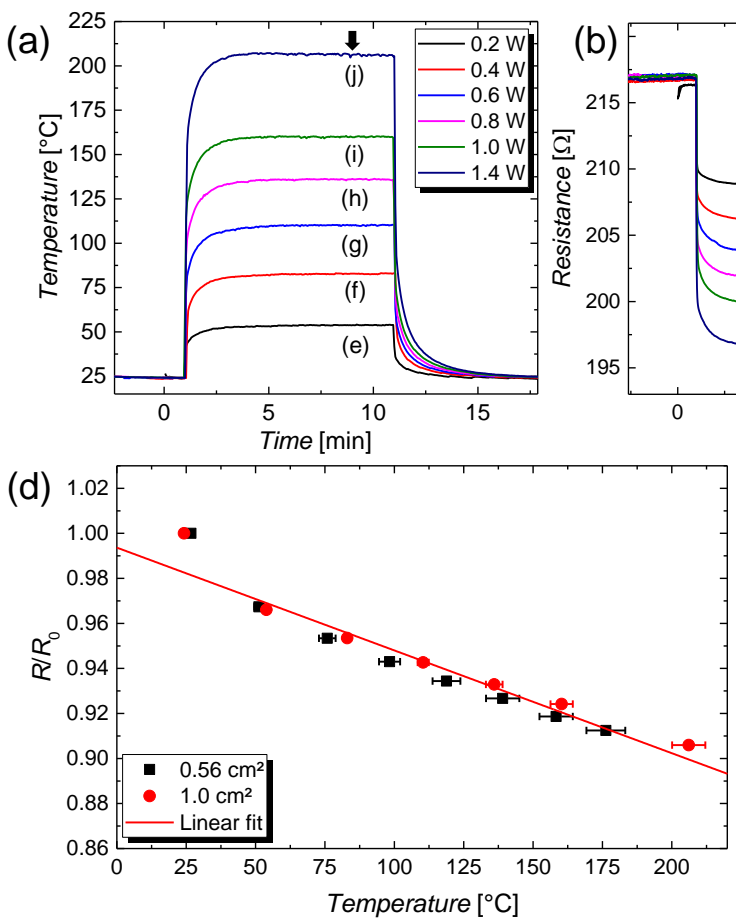
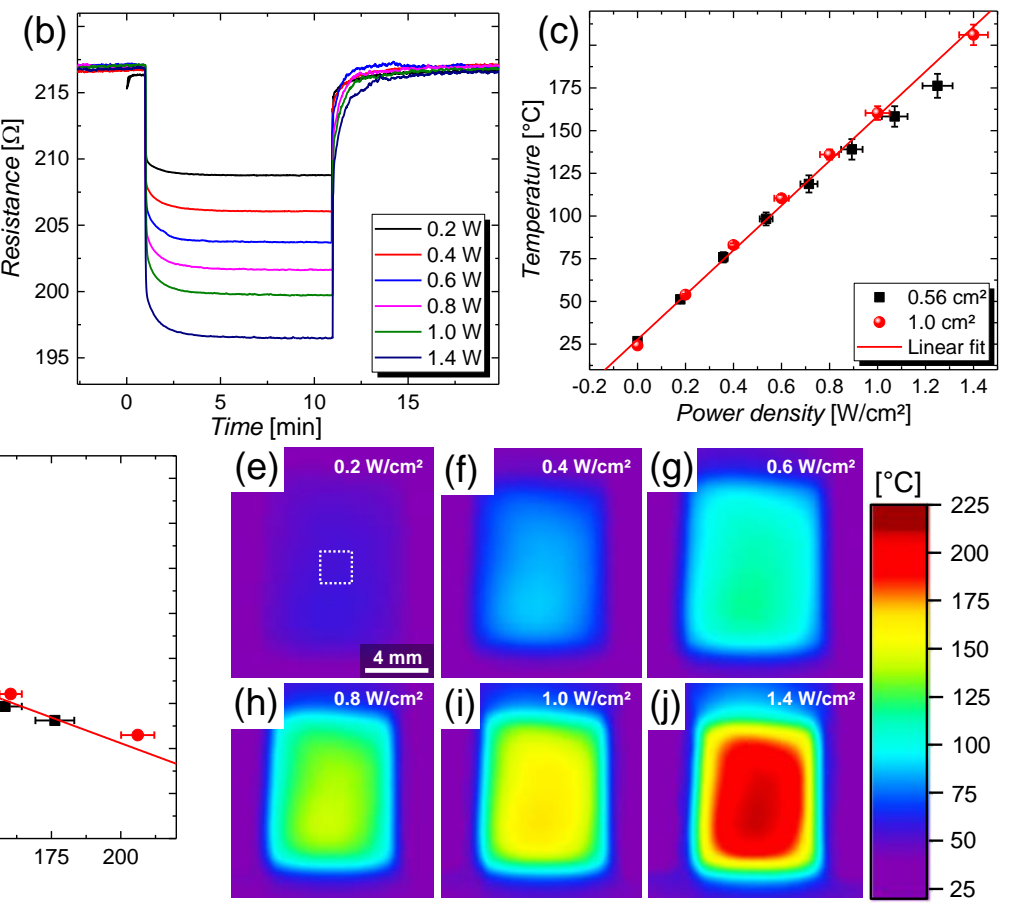

Figure 5. Transient (a) thermal and (b) resistance curves for a LIG heater on a polyimide substrate. The actively heated area is $1 \mathrm{~cm}^{2}$. The labels in (a) at the saturation temperatures 
correspond to the IR-images (e-j) extracted for each power step. (c) Temperature as a function of the applied electrical power density for two LIG heaters. The solid line represents a linear fit to the experimental data. (d) Normalized resistance $R / R_{0}$ for two LIG films as a function of the mean temperature of the heated film. The solid line represents a linear fit to the experimental data. IR-images of a LIG film heater with an actively heated area of $1 \mathrm{~cm}^{2}$ for increasing power densities of (e) 0.2 , (f) 0.4 , (g) 0.6 , (h) 0.8 , (i) 1.0 and (j) $1.4 \mathrm{~W} / \mathrm{cm}^{2}$. The area of around $2 \times 2 \mathrm{~mm}^{2}$ that was used to determine a mean value for the temperature is indicated as dashed white square in (e). The scale bar in (e) also applies to the images (f-j).

Subsequently, the transient thermal response depicted in Figure 5 (a) is modeled and the total heat transfer coefficient $h$ is determined. (Rev\#1Com\#1) The coefficient $h$ is composed of a convective heat loss $h_{\mathrm{C}}$ and a radiative heat loss $h_{\mathrm{R}}$. For simplicity and in agreement with previous works [52], [53], it is assumed that the radiative losses per unit time $P_{\mathrm{R}}$, which are described by the Stefan-Boltzman law below, can be linearized with regard to the temperature as follows:

$$
P_{\mathrm{R}}=\epsilon \cdot \sigma \cdot A\left(T^{4}-T_{0}{ }^{4}\right)=\epsilon \cdot \sigma \cdot A\left(T^{2}+T_{0}^{2}\right)\left(T+T_{0}\right)\left(T-T_{0}\right)=A \cdot h_{\mathrm{R}}\left(T-T_{0}\right)
$$

where $\epsilon$ denotes the emissivity, $\sigma$ the Stefan-Boltzmann constant, $A$ the area of the heater, $T$ the temperature on the heated side, $T_{0}$ the ambient temperature and $h_{\mathrm{R}}$ the radiative heat transfer coefficient, respectively. Similarly to previous publications, $h_{\mathrm{R}}$ is considered to be a constant since the convective heat losses (Rev\#1Com\#1) that also rise linearly with the temperature [46] are the dominating. This assumption eases the derivation of a simple analytical solution for the differential equation below. The temperature response can be modelled by considering the in- and outgoing heat fluxes at the film-heater/air interface, as sketched in Figure S4, for the ON state:

$$
c_{\mathrm{p}} \cdot \rho \cdot V \cdot \mathrm{d} T=P_{\mathrm{el}} \cdot \mathrm{d} t-2 h A\left(T-T_{0}\right) \mathrm{d} t \quad\left(P_{\mathrm{el}}>0\right)
$$

where $c_{\mathrm{p}}$ denotes the isobaric specific heat capacity, $\rho$ the mass density and $V$ the volume of the polyimide film, respectively, and $P_{\mathrm{el}}$ the electrical input power. For the OFF state, i.e. without electrical input power, Eq. 2 is reduced to:

$$
c_{\mathrm{p}} \cdot \rho \cdot V \cdot \mathrm{d} T=-2 h A\left(T-T_{0}\right) \mathrm{d} t \quad\left(P_{\mathrm{el}}=0\right)
$$

A factor of 2 is included to consider the front and the back sides of the film heater. For Eq. 2 and 3 , simple analytical solution can be derived, as follows:

$$
T(t)=T_{0}+\frac{P_{\mathrm{el}}}{2 h A}\left(1-e^{-\frac{2 h A}{c_{\mathrm{p}} \cdot \rho \cdot V} \cdot\left(t-t_{\mathrm{on}}\right)}\right)=T_{0}+T_{\mathrm{diff}}\left(1-e^{-\frac{\left(t-t_{\mathrm{on}}\right)}{\tau}}\right) \quad\left(P_{\mathrm{el}}>0\right)
$$


where $t_{\mathrm{on}}$ denotes the on-switching time, $T_{\text {diff }}$ the increase in temperature due to heating and $\tau$ the response time, which is defined as $\tau=2 c_{\mathrm{p}} \cdot \rho \cdot V / h A=2 c_{\mathrm{p}} \cdot \rho \cdot d / h$, where $d$ denotes the thickness of the heater. For the off-state, following expression is derived:

$$
T(t)=T_{0}+\left(T_{\text {sat }}-T_{0}\right) e^{-\frac{\left(t-t_{\text {off }}\right)}{\tau}} \quad\left(P_{\text {el }}>0\right)
$$

where $t_{\text {off }}$ denotes the off-switching time. Eq. 4 and 5 were used to fit the experimental data for the transient thermal response of the LIG heater shown in Figure 5 (a). The results are drawn in Figure $\mathbf{S 3}$ as bold red lines (ON state) and dashed red lines (OFF state) for all the electrical powers and in the inset in Figure 6 (b) exemplarily for three different powers. The fitting of the experimental data allows determining $\tau$ for the $\mathrm{ON}$ and the OFF state of the heater, as plotted in Figure 6 (a). $\tau$ is defined as the time it takes until the temperature of the heater increases by $(e-1) / e \cdot 100 \% \approx 63 \%$ with respect to the absolute temperature increase $T_{\text {diff. }}$ From Figure 6 (a) it can be concluded that $\tau_{\text {OFF }}$ for the OFF states of the heater stays in a narrow range from $18 \mathrm{~s}$ to $22 \mathrm{~s}$ for all temperatures, whereas $\tau_{\mathrm{ON}}$ for the ON states is gradually decreasing from around $20 \mathrm{~s}$ to $8 \mathrm{~s}$, in a temperature range from 50 to $207^{\circ} \mathrm{C}$. This deviation for $\tau_{\mathrm{OFF}}$ and $\tau_{\mathrm{ON}}$ was reported by $\mathrm{Ji}$ et al. in a previous study on thin-film heaters. It can be attributed to the oversimplified Eqs. 4 and 5 that are based on the assumption that the temperature dependence of $c_{\mathrm{p}}, \rho, d$ and $h$ can be neglected. The temperature dependence of the heat loss $h$ shown in Figure 6 (b) is solely determined by $T_{\text {diff }}$, in accordance with Eq. 4. For our heaters, $h$ lies in a range of 35 to $39 \mathrm{~W} / \mathrm{m}^{2} \mathrm{~K}$ and gradually increases over a temperature range of 50 to $207^{\circ} \mathrm{C}$. These values for $h$ compare well to the ones reported in the literature for carbon-based film heaters made of multi-walled CNTs on PET $\left(22 \mathrm{~W} / \mathrm{m}^{2} \mathrm{~K}\right)$ [54], single-walled CNTs on glass $\left(33-100 \mathrm{~W} / \mathrm{m}^{2} \mathrm{~K}\right)$ [51], and CNT/AgNW composite (11-18 W/m² $\mathrm{K})$ [55]. In agreement with Eq. 4, for a constant electrical power, a low $h$ leads to a high saturation temperature but a low heat transfer to the surroundings via radiation or conduction.
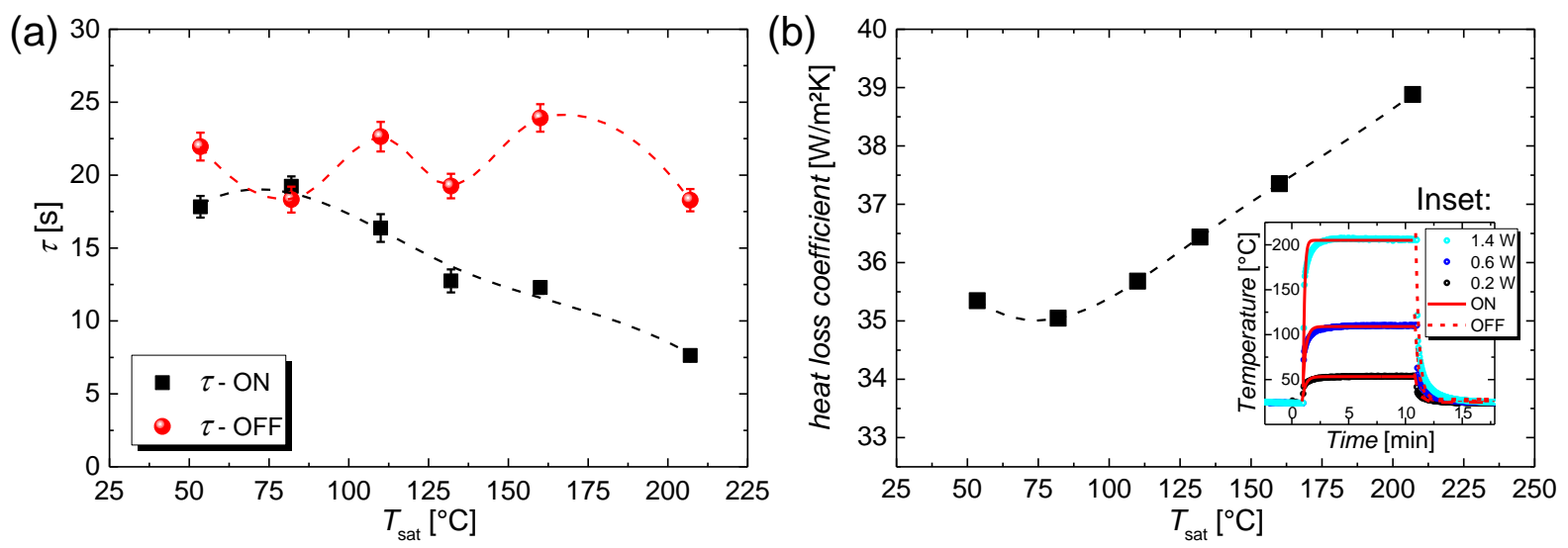
Figure 6. (a) Response times $\tau$ for the ON and the OFF state of the LIG heater shown in Figure 5 (a), defined in accordance with Eqs. 5 and 6, as a function of the saturation temperatures. (b) Heat loss coefficients for increasing saturation temperatures, extracted from fitting Eq. 4 to the transient thermal responses illustrated in Figure 5 (a). The inset in (b) depicts fits (bold and dashed red lines) of the Eqs. 4 and 5 to the experimental data.

The temperature-dependent resistance $R$ normalized with respect to the ambient resistance $R_{0}$ at ambient temperature $T_{0}$ is illustrated in Figure 5 (d). The $R-T$ curve shows a linear dependence from slightly elevated temperatures of around $50{ }^{\circ} \mathrm{C}$ on, which yields to a temperature coefficient of $\alpha=-0.46 \pm 0.04 \mathrm{~m} \cdot{ }^{\circ} \mathrm{C}^{-1}$ that was extracted in accordance with the simple empirical formula:

$$
R(T)=R_{0}\left(1+\alpha\left(T-\mathrm{T}_{0}\right)\right)
$$

The extracted temperature coefficient is negative, as reported for polycrystalline graphite below a temperature of $1400{ }^{\circ} \mathrm{C}$ [56], and compares well to the literature values for graphite and graphene of around $-0.5 \mathrm{~m} \cdot{ }^{\circ} \mathrm{C}^{-1}$ [57], [58], for both materials. At this point, it should not be omitted that the resistance shows a large drop of around $3.3 \%$ in the temperature range of $25-50{ }^{\circ} \mathrm{C}$, which does not fit to the lower and linear decrease for $R / R_{0}$ of around $6.5 \%$ in the temperature range $50-175^{\circ} \mathrm{C}$. This behaviour is in good agreement with the finding from Figure 4, where a minimum current density is required to establish good electrical percolation. The IR-images that are used to produce the transient temperature curves are depicted in Figure 5 (e-j) for different electrical energy densities up to $1.4 \mathrm{~W} / \mathrm{cm}^{2}$. From these Figures, it is evident that the temperature distribution across the actively heated area is relatively homogeneous and shows a drastic drop at the LIG-polyimide transition.

\subsection{Thermal stability}

After studying the structural, electrical and thermal properties of the LIG heaters, their thermal stability will be investigated with regard to i) their maximum operating temperature and ii) their stability under prolonged operation for increasing current densities. To study the maximum operating temperature and in turn also the maximum electrical input power density, the normalized resistance $R / R_{0}$ shown in Figure 7 was recorded as a function of the time for step-wise increases in (a) the temperature that is induced by step-wise increases in (b) the applied power densities. For the change in resistance, two regimes that are indicated in Figure 7 (b) can be identified: i) an operation regime that can be considered as stable since the resistance shows a step-wise and ii) linear decrease in resistance with temperature, in accordance with the temperature coefficient extracted from Figure 5 (d). In this region, the temperature and power density range is around $25-200{ }^{\circ} \mathrm{C}$ and $0-2.3 \mathrm{~W} / \mathrm{cm}^{2}$, respectively. 
For a temperature and power density range of $200-400{ }^{\circ} \mathrm{C}$ and $2.3-4.5 \mathrm{~W} / \mathrm{cm}^{2}$, respectively, the heaters undergo a gradual degradation that is accompanied by an increase in resistance. Around an electrical power density of $4.5 \mathrm{~W} / \mathrm{cm}^{2}$ and a temperature of $400{ }^{\circ} \mathrm{C}$, $R / R_{0}$ shows an abrupt increase and ultimately electrical breakdown for slightly higher power densities. As shown in the SEM-images in Figure 7, this breakdown is accompanied by a change in morphology of both (c) the raw substrate and (d) the LIG film. It is evident that the maximum operation temperature is limited by the polyimide substrate, which is reported to be stable up to a temperature range of $300-400{ }^{\circ} \mathrm{C}$ [59], [60], in accordance with the literature and up to $400{ }^{\circ} \mathrm{C}$, according to the manufacturer. In contrast to polyimides, purely carbonbased allotropes exhibit a higher thermal stability. From thermogravimetric (TGA) analysis, graphite has shown to be stable up to a temperature of around $550{ }^{\circ} \mathrm{C}$, under air flow [61], whereas, from Raman measurements, mono- and bilayer graphene start to show defects around a temperature range of $500-600{ }^{\circ} \mathrm{C}$ [62]. Further, an important difference in the thermal properties is the linear thermal expansion coefficient, which is reported in the range of $(32-44) \cdot 10^{-6} /{ }^{\circ} \mathrm{C}$ for polyimide and $-8 \cdot 10^{-6} /{ }^{\circ} \mathrm{C}$ for graphene, both at room temperature [63], [64]. Since, on the one hand, the thermal expansion of the polyimide substrate is at least a factor of 5 higher than for the LIG films; the rupture of the LIG line shown in Figure 7 (d) is induced. On the other hand, the robust LIG mesh clings together the expanding polyimide substrate and induces a mechanical stress, which results in the polyimide cracks visible in Figure 7 (c). The onset of the electrical breakdown is further studied from the IR-images shown in Figure 7 that capture the moment of breakdown with respect to fully the operational device with no change in the heat distribution (Figure 7 (e)), 1 min after the onset of rapid degradation, 2 min later and after $3 \min$ (Figure 7 (f)-(h), respectively). The LIG film is burnt off on the top section (Figure 7 (f)), whereas the overall breakdown occurs on a timescale below $3 \mathrm{~min}$. The maximum achieved operation temperature under ambient conditions of around $400{ }^{\circ} \mathrm{C}$ for the LIG film heaters is superior to the one reported for other novel film heater materials. For example, heaters based on AgNWs show fragmentation in the range $250-300{ }^{\circ} \mathrm{C}$ [19], [65], [66] and those made of CuNWs readily oxidize above $100-150{ }^{\circ} \mathrm{C}$ [20], [21]. In addition, graphene and its derivatives are known for their high chemical stability, which is comparable to the one of diamond at atmospheric pressure [67]. 

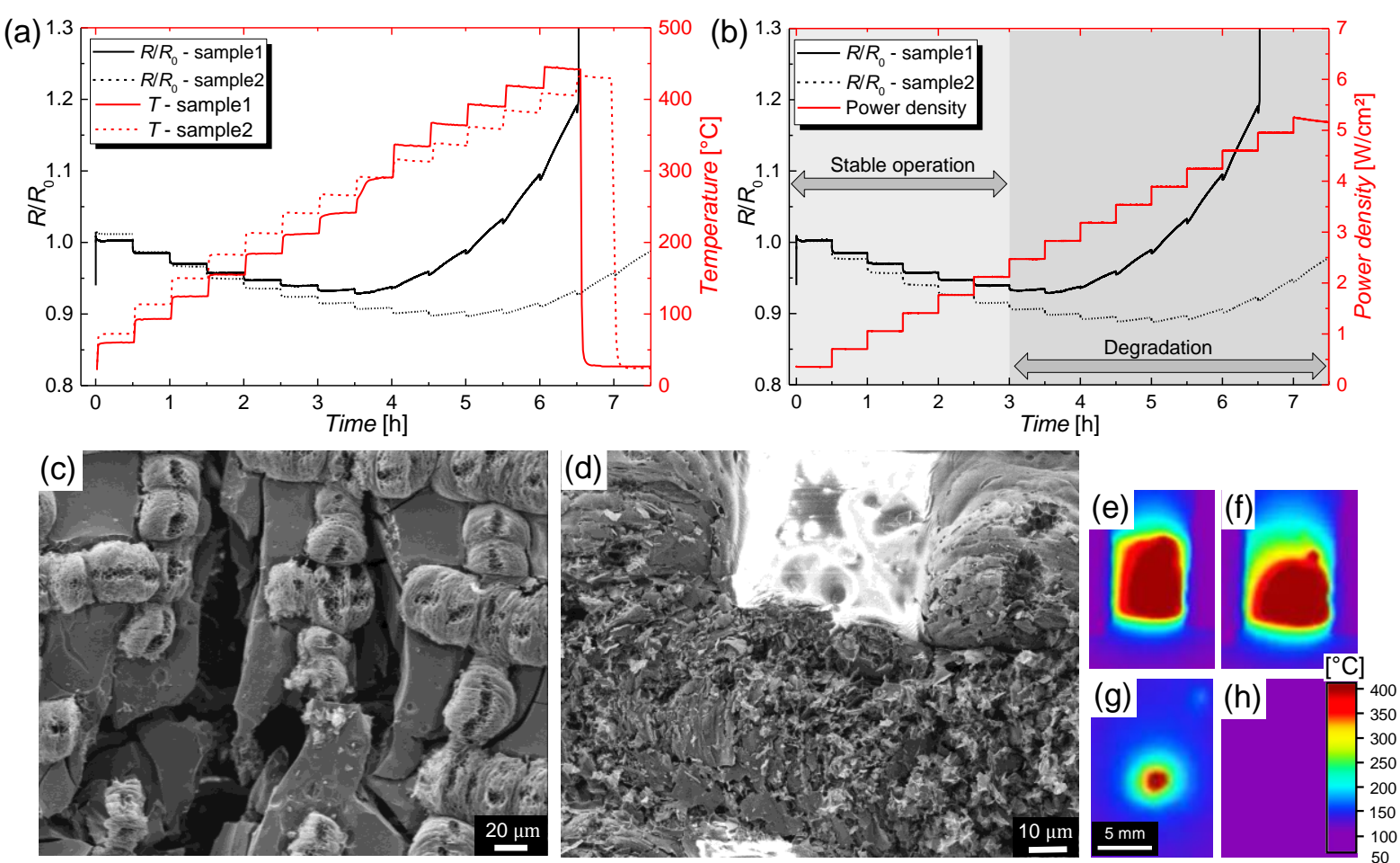

Figure 7. (a) Normalized resistance $R / R_{0}$ and temperature for two LIG film heaters as a function of the time. (b) Normalized resistance $R / R_{0}$ and power density for two LIG film heaters as a function of the time. SEM-images for a degraded LIG film heater that show (c) the rupture of the polyimide substrate and (d) the damaging of the LIG lines. (e-h) IR images that depict the moment of breakdown for a LIG film heater in time steps of 1 min between two adjacent images.

Next, the degradation of the LIG films is studied for prolonged operation under current flow, as depicted in Figure 8 (a) that shows the resistance of a LIG heater as a function of the operation time for increasing power densities. For each power density, 8 heating steps with a duration of $2 \mathrm{~h}$ are followed by cooling steps with a duration of $30 \mathrm{~min}$. The change in resistance after each heating cycle with respect to the initial resistance is shown in Figure 8 (b) as a function of the number of cycles for increasing power densities. This plot allows a rough classification of the heater into different degradation regimes. For a power density of up to $1.8 \mathrm{~W} / \mathrm{cm}^{2}$ that corresponds to a temperature of $225{ }^{\circ} \mathrm{C}$, the change in resistance lies below $4 \%$, whereas, for power densities above $2.7 \mathrm{~W} / \mathrm{cm}^{2}$ corresponding to a temperature of $250-275^{\circ} \mathrm{C}$, the change is more pronounced, as highlighted by the percentage values in Figure 8 (b). 

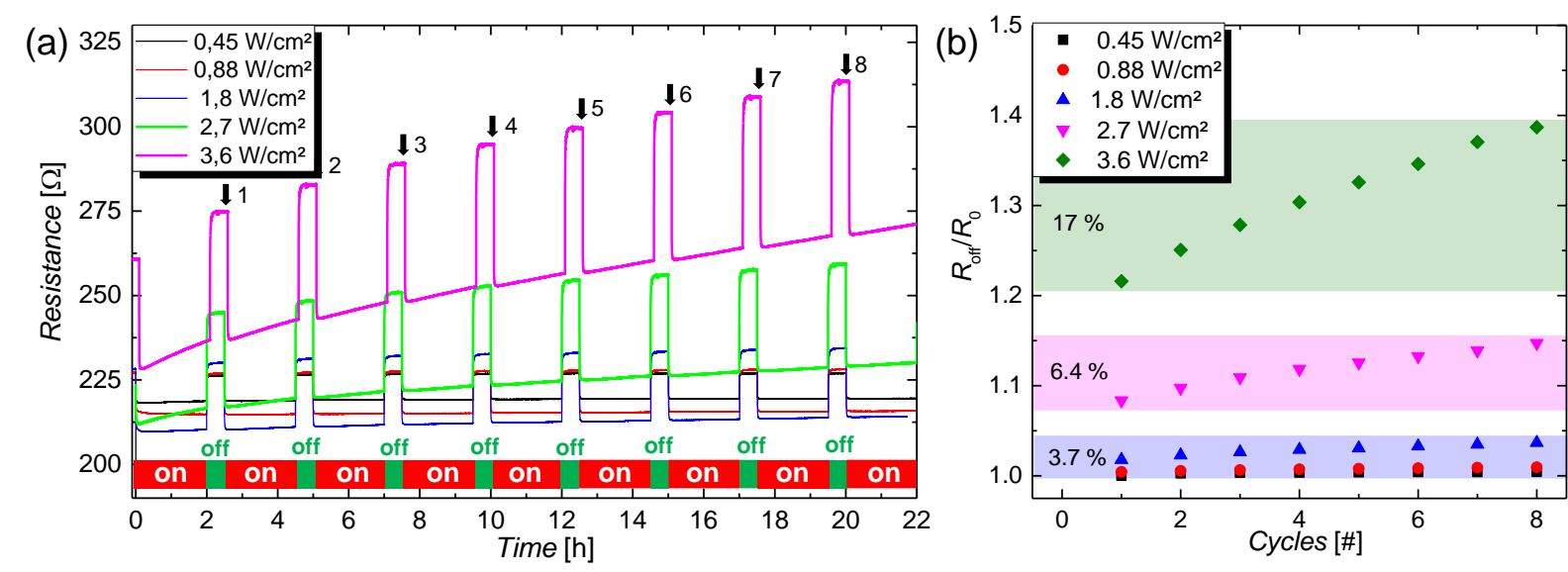

Figure 8. (a) Long-term stability test for a LIG film heater that is subjected to increasing power densities. In total, 8 cycles with $2 \mathrm{~h}$ heating and $0.5 \mathrm{~h}$ cooling per cycle were conducted for each power density step. (b) Normalized increase in resistance $R_{\text {off }} / R_{0}$ for increasing cycles and power densities. $R_{\text {off }}$ denotes the resistance in the off state of the film heater after one heating cycle.

The increase in resistance for prolonged operation of the LIG films can be attributed to two effects: i) mechanical and ii) chemical degradation. The mechanical degradation is induced by the large thermal expansion coefficient of the polyimide substrate that leads to a rupture of the LIG lines, which is gradually increasing over time. The chemical degradation is induced by the oxidation of carbon. The thermal behavior under air flow and elevated temperatures of carbon-based materials such as fullerenes (C60 and C70), diamond, carbon nanotubes and graphene was the subject of previous studies [68]-[73]. In summary, the thermal robustness of those materials can be grouped as follows:

\section{Diamond, nanotubes > graphene >C60 > C70}

From TGA measurements, Cataldo et al. observed a clear onset of the reactivity between $\mathrm{O}_{2}$ molecules and graphite in a temperature range of $400-500{ }^{\circ} \mathrm{C}$ [61]. This range is slightly higher than the temperatures that were investigated for a long-term test in this study. However, it is likely that the carbon atoms in the LIG heaters undergo a slow but gradual chemical degradation even below $400{ }^{\circ} \mathrm{C}$.

\subsection{Flexibility and adhesion}

Flexible heaters can e.g. be used for wearable electronics such as for wearable articular thermotherapy, as proposed by Choi et al. in 2015 [74]. So far, flexible thin-film heaters were fabricated using solution-processed metal nanowires such as AgNWs [75], graphitic materials such as graphene [49], [76] and CNTs as well as composite materials such as AgNWs/CNTs [55] or AgNWs/PEDOT:PSS [47]. In detail, the utilized flexible materials were polyimide 
[76], PDMS [77], PET [55], PEN [78] and a polyacrylate-based polymer [79]. The novelty in this study is that the heaters are directly produced on a bare polyimide substrate, which inherently guarantees that the active film adapts the shape of the underlying substrate. This circumstance should aid to improve the flexibility of the fabricated devices. It should be noted that, for the presented heaters, it is mainly important to achieve a uniform LIG film and, hence, a uniform heat flux and temperature distribution across the device. Thus, novel flexible and eventually also semi-transparent heaters are often fabricated by scalable spraying processes. In the case of metal nanowires, this process results in the formation of a random nanowire mesh that uniformly conducts [19], [20], [80]. Besides spray coating, other deposition techniques such as drop casting [81], vacuum filtration [77] or spinning [54] were also reported for the fabrication of self-heating films. However, these techniques possess large drawbacks like the lack of homogeneity and scalability. In the end, it should be emphasized that the versatile CNC-driven fabrication process can also be utilized to form more complex structures such as graphene-based and biocompatible interdigitated electrodes (IDEs) to fabricate biosensors, self-recovering sensors, or environmental and health monitoring systems [82]. In this work, the flexibility of the presented devices was studied for subsequent bending cycles, as shown in Figure 9 that depicts the change in resistance $R$ with respect to the initial resistance $R_{0}$ for an increasing number of bending cycles. Photos for (a) the relaxed and (b) the bent state of the film heater with a minimum bending diameter of $4 \mathrm{~mm}$ are shown in the inset of Figure 9. It can be recognized that even after 10000 bending cycles, the change in the normalized resistance is below 4\%. (Rev\#1Com\#5) It should be mentioned that there exist enormous future opportunities for flexible heaters such as for wearable devices or lowcost point-of-care chips for combinatorial studies [83]. (Rev\#1Com\#4) For the multimeter measurement, a probe current of $3 \mathrm{~mA}$ was passed through the device to establish a good electrical percolation, in agreement with Figure 4. However, of interest is also the stability of the devices in operation, i.e. when subjected to high electrical currents or power densities. For this, the same bending experiment was performed at an electrical input power density of $1 \mathrm{~W} / \mathrm{cm}^{2}$, as shown by the IR images in the inset of Figure 9 that depicts the LIG heater in (c) the relaxed and (d) the bent state. No increase in resistance or change in the IR-images could be observed after 100 bending cycles (see supporting information video S1). 


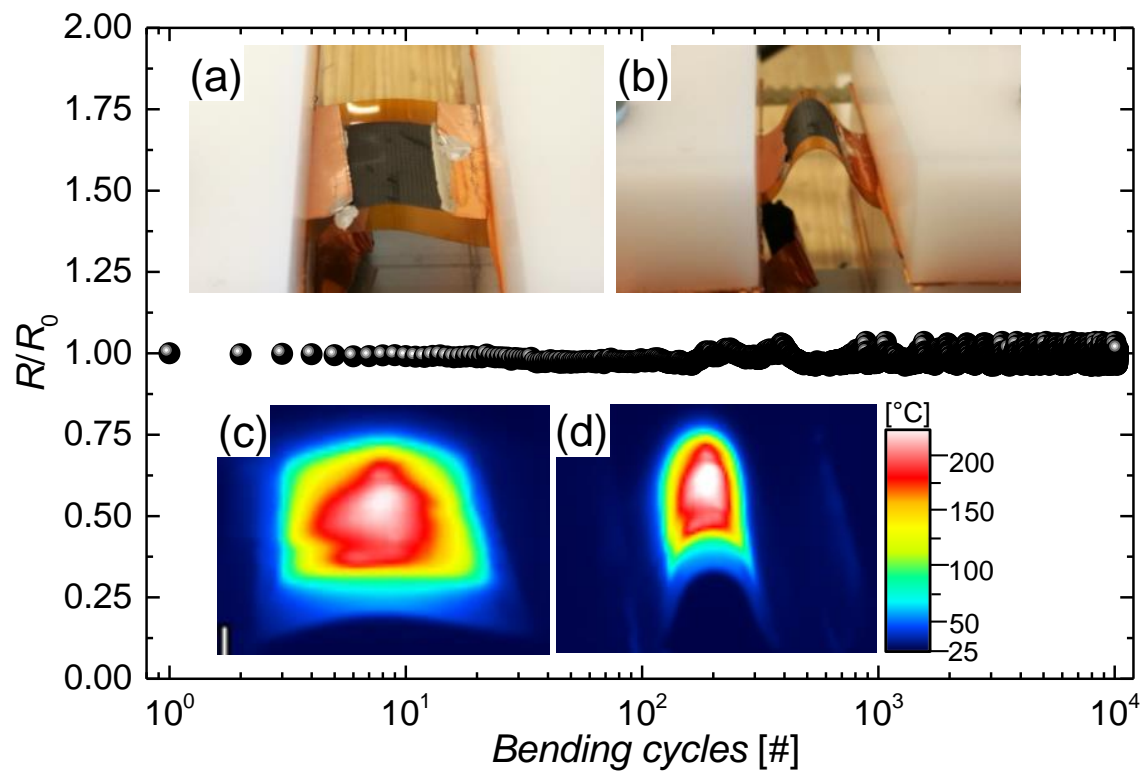

Figure 9. Change in resistance $R$ with respect to the initial resistance $R_{0}$ for an increasing number of bending cycles. The sample under test is bent to a minimum diameter of around $4 \mathrm{~mm}$. For this test, only a small probe current was applied. The inset (a) and (b) show the sample in the relaxed and bent position whereas the insets (c) and (d) show the infrared images for the LIG heater in the relaxed and bent position, respectively, subjected to an electrical power of $1 \mathrm{~W}$.

\section{Commercialization potential}

Before concluding our work, we would like to emphasize the commercial potential of the laser-scribing technique in combination with the proposed substrate for manufacturing costeffective heaters. For this, nanographene heaters with an area of $7 \times 5=35 \mathrm{~cm}^{2}$ were fabricated, as shown in Figure 10 (a), and compared with a commercial heater based on metal serpentine-structures that is depicted in Figure 10 (b). The patterned areas of the heaters are identical. For both heaters, polyimide was employed as the substrate. Electrical contacts to the nanographene heater were formed by screen printing a solution-based silver paste (Loctite 1010). Next, the two types of heaters are compared with each other with regard to the homogeneity of their heat distribution, which is depicted in Figure $\mathbf{1 0}$ for (c) the nanographene heater and (d) the commercial heater 3616107 from thermos technologies (Germany), at an electrical input power of $3.5 \mathrm{~W}$. From these images, it can be seen that our nanographene heater shows a high uniformity, whereas for the commercial heaters, hot areas are formed. (Rev\#1Com\#2) The presented LIG heaters can be fabricated under ambient conditions, whereas common thin film heaters are typically produced under high-vacuum, which is very costly and difficult to realize for larger areas [84], [85]. Besides the homogeneous heat distribution of the nanographene heater and the facile fabrication process, 
another advantage over the commercial one is its robustness to mechanical stress. For the case that the serpentine-like structure of the commercial heater is interrupted at some position, the heater is broken, whereas the nanographene heater can still be operated with a reduction in uniformity of the heat distribution and, eventually, also an increase in resistance. From an economic point of view, the laser-scribed heaters are also attractive since they are around a factor of 31 cheaper than the commercial ones (see supporting information for this estimation). Finally, despite of the already very promising robustness, it should be mentioned that our heaters are susceptible to scratching. However, we believe that this issue can easily be solved by employing polymer-based coatings such as polymethyl methacrylate (PMMA) [21] or parylene [86], which have widely been reported for encapsulation.

(a)

(c)
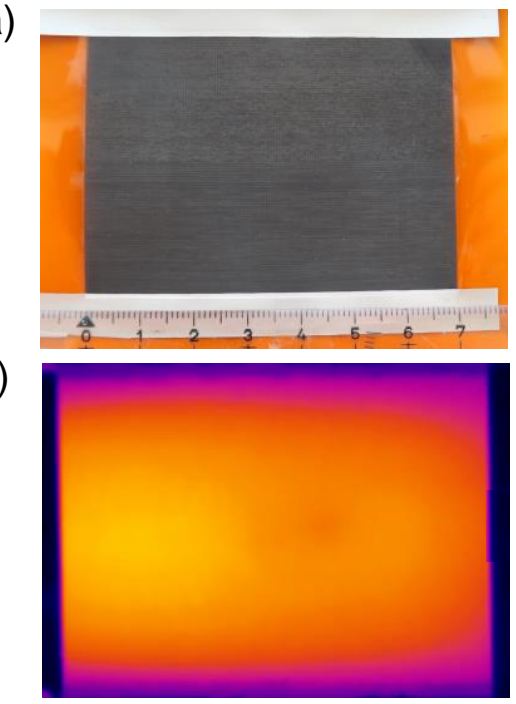

(b)

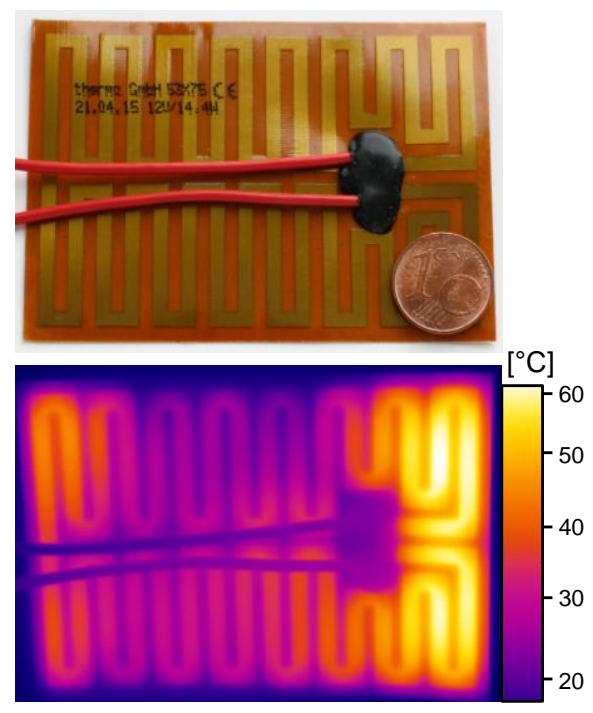

Figure 10. Photographies of (a) a photothermally scribed nanographene heater with screen printed and silver-based bias electrodes and (b) a commercial polyimide heater. Infrared images for (c) the nanographene and (d) the commercial heater.

\section{Conclusion}

In this paper, we describe the manufacturing of flexible and cost-effective heaters by an innovative and simple laser-scribing process on bare polyimide films. This technique offers a reproducible and easy fabrication process, which modified the electrical properties of such a polyimide. (Rev\#1Com\#3) In contrast to commercial flexible heaters, the LIG heaters show a much higher heat uniformity and can be fabricated under ambient conditions. The resulting material shows electrical properties comparable to the ones of graphene, such as the temperature coefficient. In particular, the fabricated heaters can operate up to $400{ }^{\circ} \mathrm{C}$, only limited by the mechanical stability of the substrate. These devices have a very stable response up to $225^{\circ} \mathrm{C}$, even while bending them. The temperature response of around $131 \mathrm{Wcm}^{2} /{ }^{\circ} \mathrm{C}$, when subjected to Joule heating, compares well or is even superior to most values reported in 
the literature. Besides, an efficient generation of high temperatures at low input powers, an important parameter for sensing applications is also the response time, which is around $8 \mathrm{~s}$ for electrical input power densities up to $1.4 \mathrm{~W} / \mathrm{cm}^{2}$.

Furthermore, the films are low-cost, environmentally friendly and the flexible heaters can be directly integrated on the substrate by laser-scribing, without requiring any extra fabrication steps such as thermal or photonic sintering. All these features open a wide range of possibilities for the presented devices that can be integrated easily in biosensor systems, environmental and health monitoring applications, reducing fabrication costs and complexity and at the same time providing a high performance.

\section{Acknowledgments}

This work was supported by the German Research Foundation (DFG) and the Technical University of Munich within the funding program Open Access Publishing and the TUM Graduate School. This work was also partially funded by Spain's Government through project TEC2017-89955-P and pre-doctoral grant FPU16/01451.

Conflicts of Interest: The authors declare no conflict of interest.

\section{References}

[1] A. C. Catto, L. F. da Silva, C. Ribeiro, S. Bernardini, K. Aguir, E. Longo, and V. R. Mastelaro, "An easy method of preparing ozone gas sensors based on $\mathrm{ZnO}$ nanorods," $R S C A d v .$, vol. 5, no. 25, pp. 19528-19533, Feb. 2015.

[2] A. C. Catto, L. F. D. Silva, M. I. B. Bernardi, S. Bernardini, K. Aguir, E. Longo, and V. R. Mastelaro, "Local Structure and Surface Properties of CoxZn1-xO Thin Films for Ozone Gas Sensing,” ACS Appl. Mater. Interfaces, vol. 8, no. 39, pp. 26066-26072, Oct. 2016.

[3] A. Falco, A. Rivadeneyra, F. C. Loghin, J. F. Salmeron, P. Lugli, and A. Abdelhalim, "Towards low-power electronics: self-recovering and flexible gas sensors," J. Mater. Chem. A, vol. 6, no. 16, pp. 7107-7113, Apr. 2018.

[4] A. Abdelhalim, M. Winkler, F. Loghin, C. Zeiser, P. Lugli, and A. Abdellah, "Highly sensitive and selective carbon nanotube-based gas sensor arrays functionalized with different metallic nanoparticles," Sensors Actuators, B Chem., vol. 220, pp. 1288$1296,2015$. 
[5] K. Handique, "Microfluidic cartridge and method of using same," US8709787B2, 14Nov-2007.

[6] K. Handique, "Microfluidic cartridge and method of making same," US9815057B2, 2004.

[7] J. Courbat, D. Briand, and N. F. de Rooij, "Reliability improvement of suspended platinum-based micro-heating elements," Sensors Actuators, A Phys., vol. 142, no. 1, pp. 284-291, Mar. 2008.

[8] I. Simon, N. Bârsan, M. Bauer, and U. Weimar, "Micromachined metal oxide gas sensors: Opportunities to improve sensor performance," Sensors Actuators, B Chem., vol. 73, no. 1, pp. 1-26, Feb. 2001.

[9] R. Triantafyllopoulou, S. Chatzandroulis, C. Tsamis, and A. Tserepi, “Alternative micro-hotplate design for low power sensor arrays," Microelectron. Eng., vol. 83, no. 4-9 SPEC. ISS., pp. 1189-1191, Apr. 2006.

[10] W.-Y. Chang and Y.-S. Hsihe, "Multilayer microheater based on glass substrate using MEMS technology," Microelectron. Eng., vol. 149, pp. 25-30, Jan. 2016.

[11] S. Khan, L. Lorenzelli, and R. S. Dahiya, "Technologies for printing sensors and electronics over large flexible substrates: A review,” IEEE Sens. J., vol. 15, no. 6, pp. 3164-3185, Jun. 2015.

[12] G. Mattana and D. Briand, "Recent advances in printed sensors on foil," Materials Today, vol. 19, no. 2. Elsevier, pp. 88-99, 01-Mar-2016.

[13] J. Courbat, M. Canonica, D. Teyssieux, D. Briand, and N. F. De Rooij, "Design and fabrication of micro-hotplates made on a polyimide foil: Electrothermal simulation and characterization to achieve power consumption in the low $\mathrm{mW}$ range," $J$. Micromechanics Microengineering, vol. 21, no. 1, p. 015014, Jan. 2011.

[14] D. Briand, A. Oprea, J. Courbat, and N. Bârsan, "Making environmental sensors on plastic foil,” Materials Today, vol. 14, no. 9. Elsevier, pp. 416-423, 01-Sep-2011.

[15] F. Molina-Lopez, A. V. Quintero, G. Mattana, D. Briand, and N. F. De Rooij, "Largearea compatible fabrication and encapsulation of inkjet-printed humidity sensors on flexible foils with integrated thermal compensation," J. Micromechanics Microengineering, vol. 23, no. 2, p. 025012, Feb. 2013. 
[16] E. Danesh, F. Molina-Lopez, M. Camara, A. Bontempi, A. V. Quintero, D. Teyssieux, L. Thiery, D. Briand, N. F. De Rooij, and K. C. Persaud, "Development of a new generation of ammonia sensors on printed polymeric hotplates," Anal. Chem., vol. 86, no. 18 , pp. 8951-8958, Sep. 2014.

[17] D. Briand, F. Molina-Lopez, A. V. Quintero, C. Ataman, J. Courbat, and N. F. De Rooij, "Why going towards plastic and flexible sensors?," in Procedia Engineering, 2011, vol. 25, pp. 8-15.

[18] J. N. Calata, G. Q. Lu, K. Ngo, and L. Nguyen, "Electromigration in sintered nanoscale silver films at elevated temperature," J. Electron. Mater., vol. 43, no. 1, pp. 109-116, Jan. 2014.

[19] M. Bobinger, D. Angeli, S. Colasanti, P. La Torraca, L. Larcher, and P. Lugli, "Infrared, transient thermal, and electrical properties of silver nanowire thin films for transparent heaters and energy-efficient coatings," Phys. status solidi, vol. 214, no. 1, p. 1600466, Jan. 2017.

[20] M. Bobinger, J. Mock, P. La Torraca, M. Becherer, P. Lugli, and L. Larcher, "Tailoring the Aqueous Synthesis and Deposition of Copper Nanowires for Transparent Electrodes and Heaters," Adv. Mater. Interfaces, vol. 4, no. 20, p. 1700568, Oct. 2017.

[21] H. Zhai, R. Wang, X. Wang, Y. Cheng, L. Shi, and J. Sun, "Transparent heaters based on highly stable Cu nanowire films," Nano Res., vol. 9, no. 12, pp. 3924-3936, 2016.

[22] H. H. Khaligh and I. a Goldthorpe, "Failure of silver nanowire transparent electrodes under current flow.," Nanoscale Res. Lett., vol. 8, no. 1, p. 235, 2013.

[23] M. Camara, P. Breuil, C. Pijolat, J. P. Viricelle, N. F. de Rooij, and D. Briand, "Tubular gas preconcentrators based on inkjet printed micro-hotplates on foil," Sensors Actuators, B Chem., vol. 236, pp. 1111-1117, Nov. 2016.

[24] S. Khan, T. P. Nguyen, M. Lubej, L. Thiery, P. Vairac, and D. Briand, "Low-power printed micro-hotplates through aerosol jetting of gold on thin polyimide membranes," Microelectron. Eng., vol. 194, pp. 71-78, Jul. 2018.

[25] A. Albrecht, A. Rivadeneyra, A. Abdellah, P. Lugli, and J. F. Salmerón, "Inkjet printing and photonic sintering of silver and copper oxide nanoparticles for ultra-lowcost conductive patterns," J. Mater. Chem. C, vol. 4, no. 16, pp. 3546-3554, 2016. 
[26] F. Romero, A. Salinas-Castillo, A. Rivadeneyra, A. Albrecht, A. Godoy, D. Morales, and N. Rodriguez, "In-Depth Study of Laser Diode Ablation of Kapton Polyimide for Flexible Conductive Substrates," Nanomaterials, vol. 8, no. 7, p. 517, Jul. 2018.

[27] Z. Peng, J. Lin, R. Ye, E. L. G. Samuel, and J. M. Tour, "Flexible and stackable laserinduced graphene supercapacitors," ACS Appl. Mater. Interfaces, 2015.

[28] J. Lin, Z. Peng, Y. Liu, F. Ruiz-Zepeda, R. Ye, E. L. G. Samuel, M. J. Yacaman, B. I. Yakobson, and J. M. Tour, "Laser-induced porous graphene films from commercial polymers," Nat. Commun., 2015.

[29] J. Zhang, M. Ren, L. Wang, Y. Li, B. I. Yakobson, and J. M. Tour, "Oxidized LaserInduced Graphene for Efficient Oxygen Electrocatalysis,” Adv. Mater., 2018.

[30] J. Zhang, M. Ren, Y. Li, and J. M. Tour, "In Situ Synthesis of Efficient Water Oxidation Catalysts in Laser-Induced Graphene," ACS Energy Lett., 2018.

[31] Z. Zhang, M. Song, J. Hao, K. Wu, C. Li, and C. Hu, "Visible light laser-induced graphene from phenolic resin: A new approach for directly writing graphene-based electrochemical devices on various substrates," Carbon N. Y., 2018.

[32] C. M. Tittle, D. Yilman, M. A. Pope, and C. J. Backhouse, "Robust Superhydrophobic Laser-Induced Graphene for Desalination Applications,” Adv. Mater. Technol., 2018.

[33] J. C. Lascovich, R. Giorgi, and S. Scaglione, "Evaluation of the sp2/sp3ratio in amorphous carbon structure by XPS and XAES," Appl. Surf. Sci., vol. 47, no. 1, pp. 17-21, Jan. 1991.

[34] R. I. R. Blyth, H. Buqa, F. P. Netzer, M. G. Ramsey, J. O. Besenhard, P. Golob, and M. Winter, "XPS studies of graphite electrode materials for lithium ion batteries," Appl. Surf. Sci., vol. 167, no. 1, pp. 99-106, Oct. 2000.

[35] D. Yang, A. Velamakanni, G. Bozoklu, S. Park, M. Stoller, R. D. Piner, S. Stankovich, I. Jung, D. a. Field, C. a. Ventrice, and R. S. Ruoff, “Chemical analysis of graphene oxide films after heat and chemical treatments by X-ray photoelectron and MicroRaman spectroscopy," Carbon N. Y., vol. 47, no. 1, pp. 145-152, 2009.

[36] A. M. Ektessabi and S. Hakamata, "XPS study of ion beam modified polyimide films," Thin Solid Films, vol. 377, no. 378, pp. 621-625, Dec. 2000.

[37] S. T. Jackson and R. G. Nuzzo, "ITO-free white OLEDs with angular color stability," 
Appl. Surf. Sci., 1995.

[38] J. A. Leiro, M. H. Heinonen, T. Laiho, and I. G. Batirev, "Core-level XPS spectra of fullerene, highly oriented pyrolitic graphite, and glassy carbon," J. Electron Spectros. Relat. Phenomena, vol. 128, no. 2-3, pp. 205-213, Feb. 2003.

[39] P. Sen Wang, T. N. Wittberg, and J. D. Wolf, “A characterization of Kapton polyimide by X-ray photoelectron spectroscopy and energy dispersive spectroscopy," J. Mater. Sci., vol. 23, no. 11, pp. 3987-3991, Nov. 1988.

[40] X. D. Huang, S. M. Bhangale, P. M. Moran, N. L. Yakovlev, and J. Pan, "Surface modification studies of Kapton ${ }^{\circledR}$ HN polyimide films," Polym. Int., vol. 52, no. 7, pp. 1064-1069, Jul. 2003.

[41] S. Stankovich, D. A. Dikin, G. H. B. Dommett, K. M. Kohlhaas, E. J. Zimney, E. A. Stach, R. D. Piner, S. B. T. Nguyen, and R. S. Ruoff, “Graphene-based composite materials," Nature, vol. 442, no. 7100, pp. 282-286, Aug. 2006.

[42] A. Domínguez-Bajo, A. González-Mayorga, E. López-Dolado, and M. C. Serrano, "Graphene-Derived Materials Interfacing the Spinal Cord: Outstanding in Vitro and in Vivo Findings," Front. Syst. Neurosci., vol. 11, p. 71, 2017.

[43] A. A. Balandin, "Thermal properties of graphene and nanostructured carbon materials," Nature Materials, vol. 10, no. 8. Nature Publishing Group, pp. 569-581, 01-Aug-2011.

[44] A. T. Bellew, H. G. Manning, C. Gomes, and M. S. Ferreira, "Resistance of Single Ag Nanowire Junctions and Their Role in the Conductivity of Nanowire Networks," ACS Nano, no. Xx, 2015.

[45] R. Waser, R. Dittmann, C. Staikov, and K. Szot, "Redox-based resistive switching memories nanoionic mechanisms, prospects, and challenges," Advanced Materials, vol. 21, no. 25-26. Wiley-Blackwell, pp. 2632-2663, 13-Jul-2009.

[46] X. Zhang, X. Yan, J. Chen, and J. Zhao, "Large-size graphene microsheets as a protective layer for transparent conductive silver nanowire film heaters," Carbon N. Y., vol. 69 , no. 2 , pp. 437-443, 2014.

[47] S. Ji, W. He, K. Wang, Y. Ran, and C. Ye, “Thermal Response of Transparent Silver Nanowire/PEDOT:PSS Film Heaters,” Small, vol. 10, pp. 4951-4960, 2014.

[48] I. S. Gainutdinov, E. A. Nesmelov, R. D. Aliakberov, and A. V. Mikhailov, "Heater 
elements based on In2O3(Sn) layers transparent in the visible region," J. Opt. Technol., vol. 71, no. 10, p. 705, Oct. 2004.

[49] J. Kang, H. Kim, K. S. Kim, S. K. Lee, S. Bae, J. H. Ahn, Y. J. Kim, J. B. Choi, and B. H. Hong, "High-performance graphene-based transparent flexible heaters," Nano Lett., vol. 11, no. 12, pp. 5154-5158, 2011.

[50] Y. H. Yoon, J. W. Song, D. Kim, J. Kim, J. K. Park, S. K. Oh, and C. S. Han, "Transparent film heater using single-walled carbon nanotubes," Adv. Mater., vol. 19, no. 23, pp. 4284-4287, 2007.

[51] T. J. Kang, T. Kim, S. M. Seo, Y. J. Park, and Y. H. Kim, “Thickness-dependent thermal resistance of a transparent glass heater with a single-walled carbon nanotube coating," Carbon N. Y., vol. 49, no. 4, pp. 1087-1093, 2011.

[52] J. J. Bae, S. C. Lim, G. H. Han, Y. W. Jo, D. L. Doung, E. S. Kim, S. J. Chae, T. Q. Huy, N. Van Luan, and Y. H. Lee, "Heat dissipation of transparent graphene defoggers," Adv. Funct. Mater., vol. 22, pp. 4819-4826, 2012.

[53] H. S. Kwak, K. Kim, B. C. Shon, H. Lee, and C.-S. Han, "Thermal Characteristics of a Transparent Film Heater Using Single-Walled Carbon Nanotubes,” J. Nanosci. Nanotechnol., vol. 10, no. 5, pp. 3512-3515, May 2010.

[54] H. S. Jang, S. K. Jeon, and S. H. Nahm, "The manufacture of a transparent film heater by spinning multi-walled carbon nanotubes," Carbon N. Y., vol. 49, no. 1, pp. 111-116, Jan. 2011.

[55] D. Kim, L. Zhu, D. J. Jeong, K. Chun, Y. Y. Bang, S. R. Kim, J. H. Kim, and S. K. Oh, "Transparent flexible heater based on hybrid of carbon nanotubes and silver nanowires," Carbon N. Y., vol. 63, pp. 530-536, Nov. 2013.

[56] T. Ota, I. Yamai, and J. Takahashi, "Positive-Temperature-Coefficient Effect in Graphite-Cristobalite Composites," J. Am. Ceram. Soc, vol. 75, no. 7, pp. 1772-76, 1992.

[57] D. C. Giancoli, Physics: Principles with Applications, vol. 1. 2004.

[58] B. Davaji, H. D. Cho, M. Malakoutian, J. K. Lee, G. Panin, T. W. Kang, and C. H. Lee, “A patterned single layer graphene resistance temperature sensor," Sci. Rep., vol. 7, no. 1, p. 8811, Dec. 2017. 
[59] R. A. Dine-hart and W. W. Wright, "Thermal Stability of Aromatic Polyimides: Factors affecting the Oxidative Stability of Poly-N,N'-(4,4'-diphenyl ether) pyromellitimide,” Br. Polym. J., vol. 3, no. July, pp. 163-168, 1971.

[60] K. Kamerbeek, G. H. Kroes, and W. Grolle, "Thermal degradation of some polyamides," Soc. Chem. Ind., vol. 19, p. Monograph no. 13, 1961.

[61] F. Cataldo, "A study on the thermal stability to $1000{ }^{\circ} \mathrm{C}$ of various carbon allotropes and carbonaceous matter both under nitrogen and in air," Fullerenes Nanotub. Carbon Nanostructures, vol. 10, no. 4, pp. 293-311, Dec. 2002.

[62] H. Y. Nan, Z. H. Ni, J. Wang, Z. Zafar, Z. X. Shi, and Y. Y. Wang, "The thermal stability of graphene in air investigated by Raman spectroscopy," J. Raman Spectrosc., vol. 44, no. 7, pp. 1018-1021, Jul. 2013.

[63] P. Hidnert, "Thermal expansion of artificial graphite and carbon," J. Res. Natl. Bur. Stand. (1934)., vol. 13, no. 1, p. 37, 1934.

[64] D. Yoon, Y. W. Son, and H. Cheong, "Negative thermal expansion coefficient of graphene measured by raman spectroscopy," Nano Lett., vol. 11, no. 8, pp. 3227-3231, Aug. 2011.

[65] M. E. T. Molares, a. G. Balogh, T. W. Cornelius, R. Neumann, and C. Trautmann, "Fragmentation of nanowires driven by Rayleigh instability," Appl. Phys. Lett., vol. 85, no. 22, pp. 5337-5339, 2004.

[66] Z. Li, J. S. Okasinski, J. D. Almer, Y. Ren, X. Zuo, and Y. Sun, “Quantitative determination of fragmentation kinetics and thermodynamics of colloidal silver nanowires by in situ high-energy synchrotron X-ray diffraction," Nanoscale, vol. 6, no. 1, pp. 365-370, 2014.

[67] J. Kestin, A course in thermodynamics (Vol. 1 and 2). CRC Press, 1978.

[68] I. M. . Ismail and S. L. Rodgers, "Comparisons between fullerene and forms of wellknown carbons," Carbon N. Y., vol. 30, no. 2, pp. 229-239, Jan. 1992.

[69] H. Werner, D. Herein, J. Blöcker, B. Henschke, U. Tegtmeyer, T. Schedel-Niedrig, M. Keil, A. M. Bradshaw, and R. Schlögl, "Spectroscopic and chemical characterisation of ‘fullerene black,"” Chem. Phys. Lett., vol. 194, no. 1-2, pp. 62-66, Jun. 1992.

[70] S. Kawata, K. Yamauchi, S. Suzuki, K. Kikuchi, H. Shiromaru, M. Katada, K. Saito, I. 
Ikemoto, and Y. Achiba, "The Origin of the ESR Signal of C60 Seen in the Powder and in Benzene Solution. The Indication of the Reaction of C60 with Oxygen Induced by Photoexcitation.," Chem. Lett., vol. 21, no. 9, pp. 1659-1662, Sep. 1992.

[71] L. P. Felipe Chibante, C. Pan, M. L. Pierson, R. E. Haufler, and D. Heymann, "Rate of decomposition of C60and C70heated in air and the attempted characterization of the products," Carbon N. Y., vol. 31, no. 1, pp. 185-193, Jan. 1993.

[72] J. C. Scanlon, J. M. Brown, and L. B. Ebert, “Oxidative stability of fullerenes,” J. Phys. Chem., vol. 98, no. 15, pp. 3921-3923, 1994.

[73] M. Wohlers, H. Werner, D. Herein, T. Schedel-Niedrig, A. Bauer, and R. Schlögl, "Reaction of C60 and C70 with molecular oxygen," Synth. Met., vol. 77, no. 1-3, pp. 299-302, Feb. 1996.

[74] S. Choi, J. Park, W. Hyun, J. Kim, J. Kim, Y. B. Lee, C. Song, H. J. Hwang, J. H. Kim, T. Hyeon, and D. H. Kim, "Stretchable Heater Using Ligand-Exchanged Silver Nanowire Nanocomposite for Wearable Articular Thermotherapy," ACS Nano, vol. 9, no. 6, pp. 6626-6633, 2015.

[75] C. Celle, C. Mayousse, E. Moreau, H. Basti, A. Carella, and J.-P. Simonato, "Highly flexible transparent film heaters based on random networks of silver nanowires," Nano Res., vol. 5, no. 6, pp. 427-433, Jun. 2012.

[76] D. Sui, Y. Huang, L. Huang, J. Liang, Y. Ma, and Y. Chen, "Flexible and transparent electrothermal film heaters based on graphene materials," Small, vol. 7, no. 22, pp. 3186-3192, Nov. 2011.

[77] S. Hong, H. Lee, J. Lee, J. Kwon, S. Han, Y. D. Suh, H. Cho, J. Shin, J. Yeo, and S. H. Ko, "Highly Stretchable and Transparent Metal Nanowire Heater for Wearable Electronics Applications," Adv. Mater., vol. 27, no. 32, pp. 4744-4751, Aug. 2015.

[78] C. Celle, C. Mayousse, E. Moreau, H. Basti, A. Carella, and J. P. Simonato, "Highly flexible transparent film heaters based on random networks of silver nanowires," Nano Res., vol. 5, no. 6, pp. 427-433, Jun. 2012.

[79] J. Li, J. Liang, X. Jian, W. Hu, J. Li, and Q. Pei, “A flexible and transparent thin film heater based on a silver nanowire/heat-resistant polymer composite," Macromol. Mater. Eng., vol. 299, no. 11, pp. 1403-1409, 2014. 
[80] M. R. Bobinger, P. La Torraca, J. Mock, M. Becherer, L. Cattani, D. Angeli, L. Larcher, and P. Lugli, "Solution-processing of Copper Nanowires for Transparent Heaters and Thermo-Acoustic Loudspeakers," IEEE Transactions on Nanotechnology, vol. 17 , no. 5, pp. 940-947, Sep-2018.

[81] J. Li, J. Liang, X. Jian, W. Hu, J. Li, and Q. Pei, “A flexible and transparent thin film heater based on a silver nanowire/heat-resistant polymer composite," Macromol. Mater. Eng., vol. 299, no. 11, pp. 1403-1409, Nov. 2014.

[82] Y. Shao, J. Wang, H. Wu, J. Liu, I. a. Aksay, and Y. Lin, "Graphene based electrochemical sensors and biosensors: A review," Electroanalysis, vol. 22, no. 10, pp. 1027-1036, 2010.

[83] R. Gupta, K. D. M. Rao, S. Kiruthika, and G. U. Kulkarni, "Visibly Transparent Heaters," ACS Appl. Mater. Interfaces, p. acsami.5b11026, 2016.

[84] Y. S. L. H. J. K. K.H. Choia J.Y. Kima, "ITO/Ag/ITO multilayer films for the application of a very low resistance transparent electrode," Thin Solid Films, 1999.

[85] C. Guillén and J. Herrero, "ITO/metal/ITO multilayer structures based on Ag and Cu metal films for high-performance transparent electrodes," Sol. Energy Mater. Sol. Cells, 2008.

[86] J. Wang, M. N. Gulari, and K. D. Wise, "A parylene-silicon cochlear electrode array with integrated position sensors," in Annual International Conference of the IEEE Engineering in Medicine and Biology - Proceedings, 2006, pp. 3170-3173.

\section{Supporting Information for}

\section{Flexible and robust laser-induced graphene heaters photothermally scribed on bare polyimide substrates}

Marco R. Bobinger ${ }^{1}$, , Francisco J. Romero ${ }^{2}$, Alfonso Salinas-Castillo ${ }^{3}$, Markus Becherer ${ }^{1}$, Paolo Lugli ${ }^{3}$, Diego P. Morales ${ }^{2}$, Noel Rodríguez ${ }^{2}$ and Almudena Rivadeneyra ${ }^{1} *$

${ }^{1}$ Institute for Nanoelectronics, Technical University of Munich, 80333 Munich, Germany 
${ }^{2}$ Pervasive Electronics Advanced Research Laboratory (PEARL), Dept. Electronics and Computer Technology, University of Granada, 18071 Granada, Spain

${ }^{3}$ Dept. Analytical Chemistry, University of Granada, 18071 Granada, Spain

${ }^{4}$ Faculty of Science and Technology, Free University of Bolzano, 39100 Bolzano -Bozen, Italy

Corresponding author e-Mails: marco.bobinger@tum.de and almudena.rivadeneyra@tum.de

The XPS survey scans over an area of around $5 \times 5 \mathrm{~mm}^{2}$ for polyimide substrate (black) before and (red) after laser ablation are depicted in Figure S1. The C 1s, N 1s and O 1s core level peaks that are associated with carbon, nitrogen, and oxygen-containing specimen, which are all present in the polyimide film, can clearly be identified.

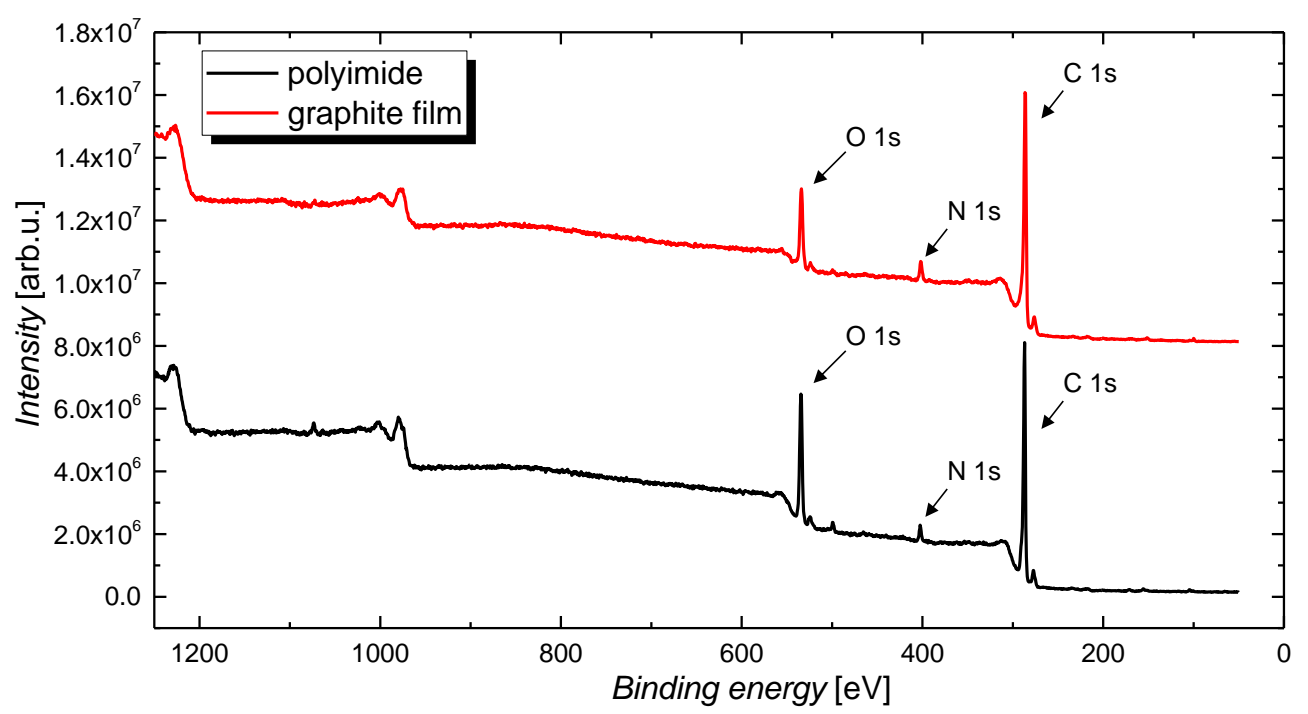

Figure S1. XPS survey scan for polyimide Kapton ${ }^{\circledR}$ HN (DuPontTM) substrate before (black) and after laser ablation (red). The relevant core-level peaks $\mathrm{O} 1 \mathrm{~s}, \mathrm{~N} 1 \mathrm{~s}$ and $\mathrm{C} 1 \mathrm{~s}$ that are associated with oxygen, nitrogen, and carbon species are indicated by arrows.

XPS high-resolution scans are shown in Figure S2 for the (a) C 1s, (b) O 1s and (c) N 1s peak along with (d) the concentrations for each element. The concentrations were determined by considering the relative sensitivity factors (RSF) for the $\mathrm{C} 1 \mathrm{~s}, \mathrm{O} 1 \mathrm{~s}$ and $\mathrm{N} 1 \mathrm{~s}$ peaks of $0.25,0.66$ and 0.42 [1], respectively. All spectra were normalized by their area and weighted with the determined concentration of the respective element. From table (d) it can be concluded that the concentrations extracted for the polyimide film are in very good agreement with the concentrations expected by considering the chemical formula of polyimide, i.e. $\mathrm{C}_{22} \mathrm{H}_{11} \mathrm{~N}_{2} \mathrm{O}_{5}$. For this estimate, the hydrogen content was neglected since it cannot be resolved by XPS. The experimentally determined concentrations for nitrogen are lower than expected, which can be attributed to residual contamination and a thin water layer that is present on most films. The contamination and water film contribute to an increase in the $\mathrm{C} 1 \mathrm{~s}$ and $\mathrm{O} 1 \mathrm{~s}$ signal, which in turn leads to a decrease of the $\mathrm{N} 1 \mathrm{~s}$ signal. 

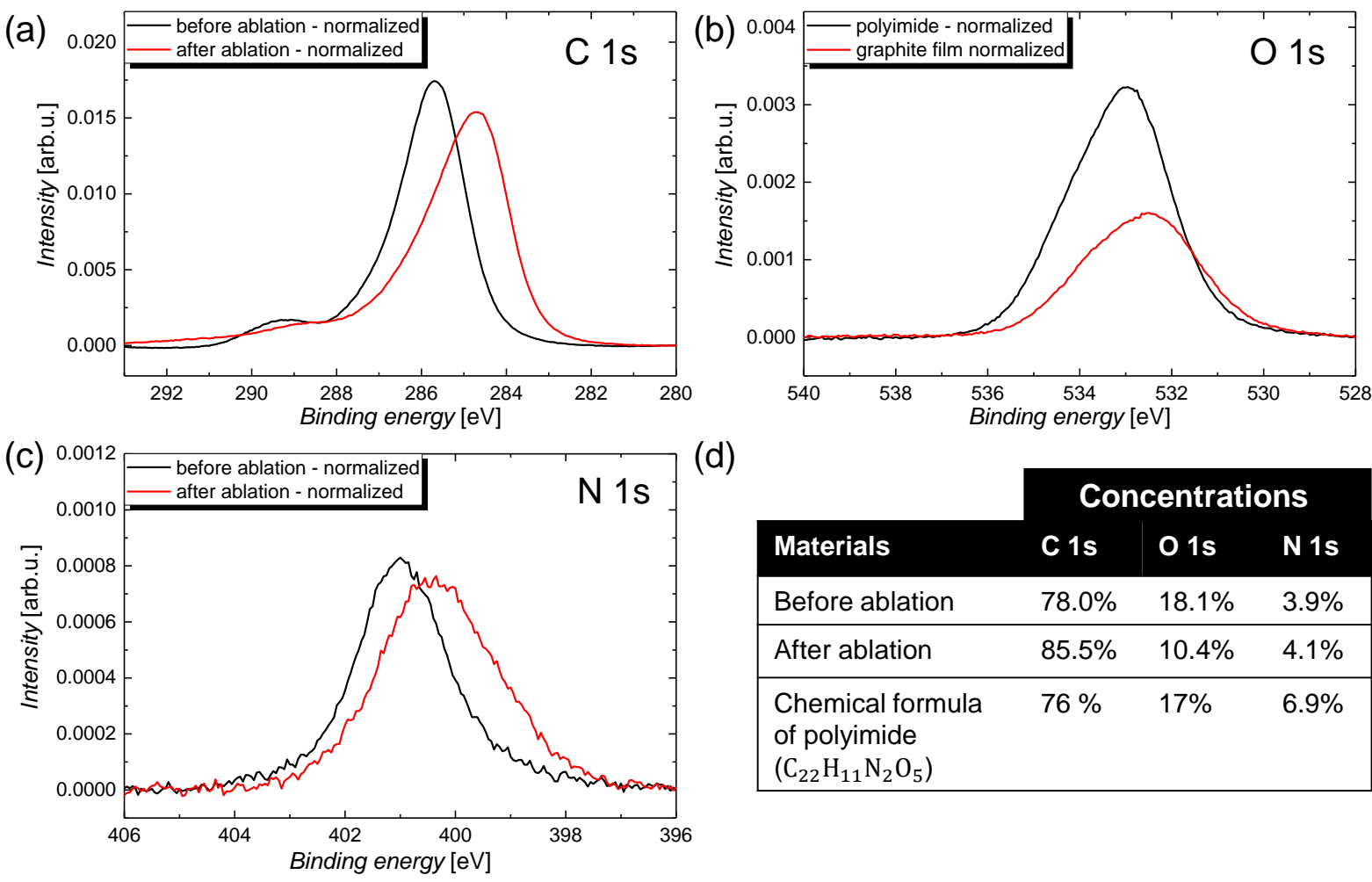

(d)

\begin{tabular}{|llll|}
\hline \multirow{2}{*}{} & \multicolumn{3}{c|}{ Concentrations } \\
\hline Materials & C 1s & 0 1s & N 1s \\
\hline Before ablation & $78.0 \%$ & $18.1 \%$ & $3.9 \%$ \\
\hline After ablation & $85.5 \%$ & $10.4 \%$ & $4.1 \%$ \\
\hline $\begin{array}{l}\text { Chemical formula } \\
\text { of polyimide } \\
\left(\mathrm{C}_{22} \mathrm{H}_{11} \mathrm{~N}_{2} \mathrm{O}_{5}\right)\end{array}$ & $76 \%$ & $17 \%$ & $6.9 \%$ \\
\hline
\end{tabular}

Figure S2. High-resolution XPS spectra for the (a) C 1s, (b) O 1s and (c) N 1s peaks before black and after laser ablation (red). (d) Table that summarizes the concentrations for carbon, oxygen and the nitrogen-related specimen in the polyimide sample i) before, ii) after ablation and iii) the expected values, in accordance with the chemical formula.

Table S1. Summary for the different contributions of the deconvoluted C 1s raw spectra shown in Figure 2.

\begin{tabular}{|l|l|l|l|l|l|l|}
\hline & \multicolumn{6}{|c|}{ Concentrations } \\
\hline Contributions & $\begin{array}{l}\text { C-C sp } \\
(284.6 \mathrm{eV})\end{array}$ & $\begin{array}{l}\mathrm{C}-\mathrm{C} \mathrm{sp} \\
(285.6 \mathrm{eV})\end{array}$ & $\begin{array}{l}\mathrm{C}-\mathrm{O} \\
(286.6 \mathrm{eV})\end{array}$ & $\begin{array}{l}\mathrm{O}-\mathrm{C}-\mathrm{O} \\
(287.6 \mathrm{eV})\end{array}$ & $\begin{array}{l}\mathrm{O}-\mathrm{C}=\mathrm{O} \\
(289 \mathrm{eV})\end{array}$ & $\begin{array}{c}\pi-\pi^{*} \\
(291 \mathrm{eV})\end{array}$ \\
\hline Polyimide & $0 \%$ & $71.9 \%$ & $7.6 \%$ & $13.4 \%$ & $7.1 \%$ & $0 \%$ \\
\hline LIG film & $56.6 \%$ & $24 \%$ & $7.2 \%$ & $4.0 \%$ & $5.8 \%$ & $2.4 \%$ \\
\hline
\end{tabular}




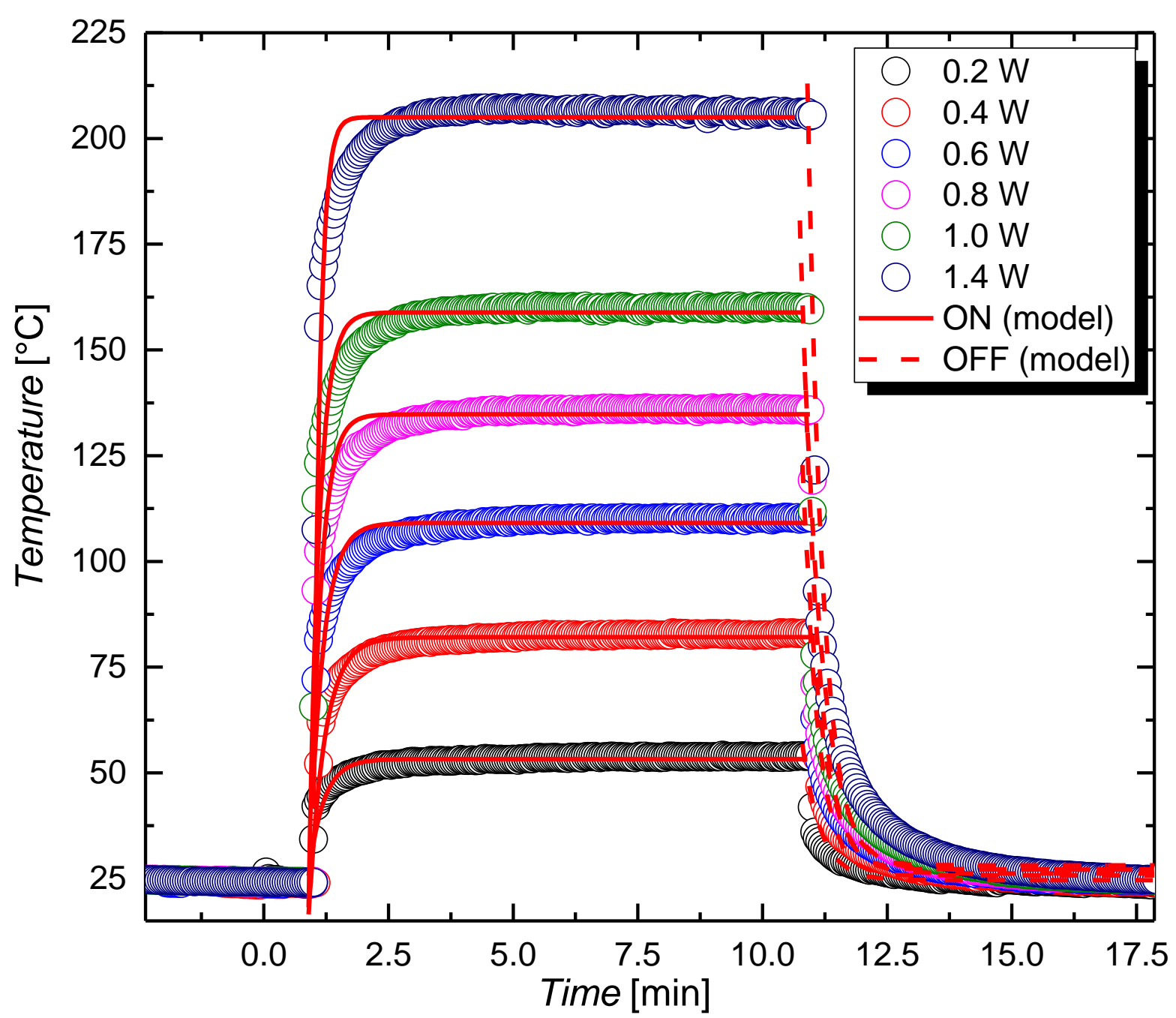

Figure S3. Transient thermal temperature responses of the LIG heater shown in Figure 5 (a). In agreement with the Eqs. 4 and 5, the analytical expressions of the temperature-time dependence for the ON (bold red line) and the OFF (dashed red line) states were fitted to the experimental data. 


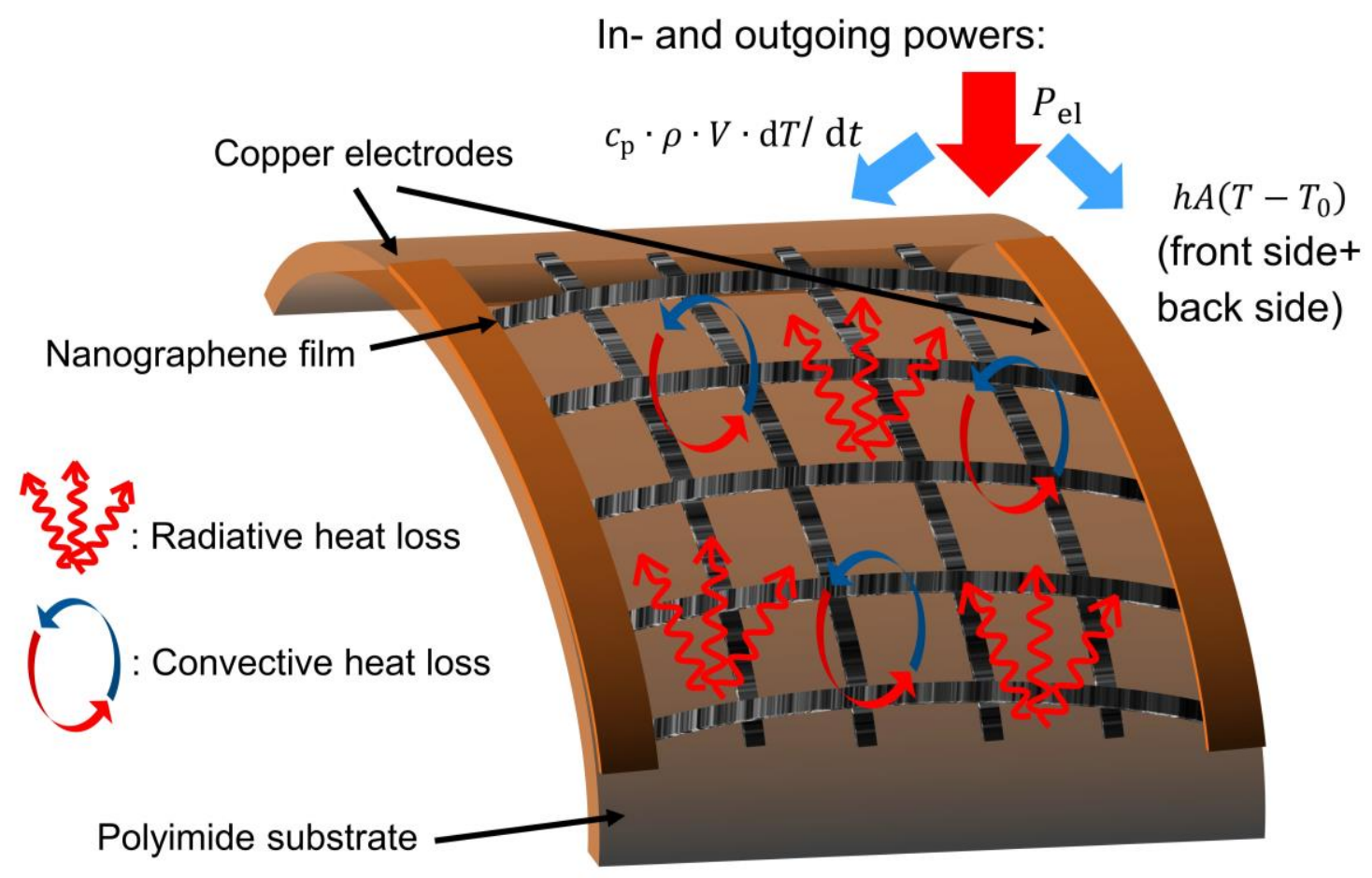

Figure S4. Schematic of the LIG heater that shows the structure as well as the heat losses composed of radiative and convective losses. The in- and outgoing powers are indicated by the red arrow and the blue arrows, respectively, in agreement with Eq. 3.

\section{Estimation of the LIG heater costs:}

The commercial polyimide heater was purchased from www.conrad.de (order number: 1594183 62) for $20.38 €$. The price for the polyimide foil purchased from www.cshyde.com is around $0.014 € / \mathrm{cm}^{2}$, whereas the $\mathrm{CNC}$ unit costs $160 €$. The power consumption can be neglected for a cost estimate. Considering an area of $35 \mathrm{~cm}^{2}$ for the heaters the fabrication of a total of 10.000 units, the price per heater can be estimated to be $0.65 €$, which is around a factor of 31 lowered than the price for the commercial heater. 